\title{
EL PROCESO DE INTENSIFICACIÓN EN LA TRANSICIÓN PAMPEANO- PATAGONICA ORIENTAL. DISCUSIÓN Y PERSPECTIVAS COMPARATIVAS CON REGIONES ALEDAÑAS.
}

\section{THE PROCESS OF INTENSIFICATION IN THE EASTERN PAMPEAN- PATAGONIAN TRANSITION. DISCUSSION AND COMPARATIVE PERSPECTIVES}

\author{
Luciana Stoessel $^{1}$ y Gustavo Martínez ${ }^{2}$ \\ 1. INCUAPA-CONICET. Facultad de Ciencias Sociales, UNICEN. E-mail: lstoesse@soc.unicen.edu.ar \\ 2. INCUAPA-CONICET. Facultad de Ciencias Sociales, UNICEN. E-mail: gmartine@soc.unicen.edu.ar
}

Presentado el: 19/05/2014 - Aceptado el: 05/11/2014

\begin{abstract}
Resumen
El concepto de intensificación ha sido usado y explorado en diversas regiones de Argentina (e.g., NOA, COA, NE, Pampa, Fuego-Patagonia, etc.) desde hace aproximadamente 15 años. En este trabajo se resume cómo ha sido concebido y aplicado el concep to en la disciplina de acuerdo a diferentes enfoques teóricos-metodológicos. Se presenta el caso de estudio del curso inferior del río Colorado, en el área de transición pampeano patagónica oriental, en el que este proceso ha sido evaluado. En función de esto, y a pesar de que la aplicación y evaluación del concepto ha sido dispar, se analiza la información sobre el proceso en sectores vecinos, como las subregiones Pampa Húmeda (particularmente las áreas Interserrana y Sur), Pampa Seca y la parte más septentrional del NE Patagónico. Se concluye que el proceso de intensificación y su discusión se mantuvo vigente a través del tiempo en las agendas de investigación. En este sentido, se observa una preocupación por la aplicación de metodologías sensibles para discutir la existencia del proceso y su impacto en las subsistencias areales y/o regionales. Finalmente, el análisis de este proceso no solo se ha centrado en aspectos económicos, sino en la relación entre estos últimos, el ambiente y las condiciones socio-demográficas e históricas de los cazadoresrecolectores del Holoceno tardío.
\end{abstract}

Palabras claves: Intensificación, Holoceno tardío, Pampa, Norpatagonia 


\begin{abstract}
Since about 15 years ago the concept of intensification has been used and explored in several regions of Argentina (e.g., NOA, COA, NE, Pampa, Fuego-Patagonia). This paper summarized how the concept has been conceived and applied in the discipline according to different theoretical and methodological frameworks. As a case study we present the data and results obtained from the lower course of the Colorado River, in the Eastern Pampa-Patagonia transition, in which the intensification process has been discussed. The evaluation of this process has been uneven in neighboring areas and sub-regions. A summary of the state of the art of the application and proposed models regarding the intensification process for the Humid Pampa (Interserrana and South areas), Dry Pampas and Northeastern Patagonia is presented. It is concluded that the process of intensification and its discussion remained active on research agendas through time. In this sense, it is observed the existence of a concern about the application of useful and sensitive methodologies in order to discuss this process and its impact on the characterization of local and regional subsistence patterns. Finally, the analysis of the intensification process has not only been focused on subsistence and economic aspects, but on the relationship among the latter, as well as with the environmental, socio-demographic and historical backgrounds of the Late Holocene hunter-gatherers.
\end{abstract}

Key words: Intensification, Late Holocene, Pampa, Northern Patagonia

\title{
Introducción
}

Intensificación ha sido un concepto principalmente utilizado para dar cuenta de los cambios ocurridos en la subsistencia en distintas partes del mundo, principalmente aquellos sucedidos durante el Holoceno tardío (Bender 1981; Betts y Friesen 2004; Binford 2001; Broughton 1994, 1997; Butler y Campbell 2004; Holly 2005; Janetski 1997; Jones 2009; Leach 1999; Lourandos 1983, 1997; Nagaoka 2005; Price y Brown 1985; Williams 1987; entre otros). En nuestro país, el concepto ha sido explorado en regiones diversas (NOA, COA, NE, Pampa, Fuego-Patagonia, etc.) donde se han desarrollado diferentes tipos de economías, tanto cazadoras-recolectoras como productoras de alimentos (Álvarez 2014; González 2005; Loponte y Acosta 2004; Martínez 1999; Martínez y Gutiérrez 2004; Miotti 2012; Miotti y Salemme 1999; Neme 2007; Otaola 2013; Quintana y Mazzanti 2001; Rivero et al. 2010; Stoessel 2012a; Yacobaccio 2006; Zangrando 2009).

Si bien se han propuesto distintas conceptualizaciones o definiciones con matices diferentes acerca del concepto de intensificación (ver debajo), una de las más utilizadas señala que es el proceso por el cual los grupos humanos obtienen más recursos en una unidad espacio-temporal determinada (Betts y Friesen 2004; Binford 2001; Morrison 1994). El abordaje zooarqueológico del mismo se puede focalizar a través del estudio de dos aspectos del registro faunístico, los cuales no ocurren necesariamente de manera simultánea, aunque tampoco son excluyentes (Prendergast et al. 2009). El primero de ellos, hace referencia al espectro de especies consumidas. Como parte de este proceso, por un lado, se puede incrementar el número de especies explotadas, generando una diversificación de la dieta y, por el otro, dentro de un escenario donde la subsistencia se concentre en uno o en escasos recursos, en un contexto de mayor inversión laboral pueden generarse estrategias de especialización (Bett y Friesen 2004; Binford 2001; Broughton 1994, 1997; Morrison 1994; Prendergast et al. 2009). Con respecto al segundo aspecto, la intensificación también puede implicar un aprovechamiento más intensivo de las carcasas (e.g., ungulados) para maximizar su aporte nutricional (e.g., consumo de nutrientes como médula y grasa ósea), lo cual genera conjuntos faunísticos altamente fragmentados (Burger et al. 2005; Butler y Campbell 2004; Janetski 1997; Nagaoka 2005; Prendergast et al. 2009). 
Por otro lado, más allá de los cambios en la explotación de recursos faunísticos, la intensificación entendida como un proceso es un fenómeno complejo que puede involucrar modificaciones en distintas esferas (e.g., tecnología, asentamiento, movilidad, etc.) que también deben ser evaluadas para comprender los cambios en la subsistencia (Ames 1985, 1994; Binford 2001; Lourandos 1983, 1997). Sin embargo, no hay definiciones únicas acerca del concepto de intensificación y sus implicancias. En este sentido, ha sido frecuentemente utilizado tanto para referirse a un acontecimiento específico, vinculado a la maximización en la explotación de un recurso o de varios (e.g., "resource intensification", "economic intensification" "intensification of production", etc.) como también, desde una concepción más amplia, para hacer alusión a un proceso que puede involucrar múltiples estrategias que no necesariamente se ponen en funcionamiento a partir de factores económicos. Debido a los diferentes usos del concepto, los cuales generalmente están influenciados por las perspectivas teóricas adoptadas, es fundamental establecer definiciones claras acerca de qué se entiende por intensificación así como también cuáles son las variables e indicadores utilizados para su análisis.

Es por esto, que este trabajo tiene los siguientes objetivos: a) discutir el concepto de intensificación según ha sido usado en la disciplina de acuerdo a diferentes marcos teóricometodológicos; b) presentar un caso de estudio, el del curso inferior del río Colorado en el área de transición pampeano patagónica oriental, en el que se llevó a cabo un análisis de este proceso; c) analizar y discutir cómo ha sido abordado este proceso en áreas vecinas, como las subregiones Pampa Húmeda (particularmente las áreas Interserrana y Sur), Pampa Seca y el sector más septentrional del NE Patagónico. En cada caso, se evaluarán los conceptos usados y su utilidad así como los indicadores que han sido empleados según marcos teóricos y conceptuales particulares. Finalmente, se describirán perspectivas futuras y aquellos puntos teóricos y metodológicos que deberían ser reforzados para un mejor abordaje del proceso en estas regiones.

\section{Enfoques teóricos}

El estudio del desarrollo del proceso de intensificación ha sido abordado desde distintos enfoques teóricos que pueden ser incluidos, en términos generales dentro de dos perspectivas: los enfoques ecológicos (Betts y Friesen 2004; Broughton 1994, 1997; Butler y Campbell 2004; Janetski 1997; Leach 1999, entre otros) y los enfoques orientados socialmente (Bender 1981; Holly 2005; Lourandos 1983, 1997; Minnegal y Dwyer 1998; Williams 1987, entre otros). Los primeros, han utilizado el concepto de intensificación con diferentes implicancias, por un lado, para hacer referencia a un incremento en la productividad por unidad de tierra que sería lograda a través de mecanismos culturales (e.g., tecnología, organización del trabajo, etc.) aumentando, en consecuencia la foraging efficiency. Por otro, se encuentran los enfoques que evalúan la intensificación a partir de los modelos de forrajeamiento óptimo. Desde estas perspectivas, la intensificación produciría una declinación en la foraging efficiency, debido a que si bien se incrementa la productividad por unidad de tierra, los costos son mayores que los beneficios obtenidos, es decir, los individuos deben trabajar más y gastar más energía como parte del proceso (Butler y Campbell 2004). En general, los modelos propuestos desde los enfoques ecológicos están basados en principios derivados de la teoría del forrajeamiento óptimo y sus modelos (e.g., modelo de amplitud de dieta, modelo de selección de presas, teorema del valor marginal, modelo de lugar central), entre los cuales uno de los más utilizados es el de amplitud de dieta. Este se basa en la construcción de rankings, en los que la posición que ocupan las distintas especies está determinada por la relación entre el 
retorno energético obtenido de cada una de ellas y los costos que implica su obtención y procesamiento. Este modelo predice que los individuos seleccionarán a aquellos recursos que ocupan los lugares más altos en los rankings en términos de retorno energético, mientras que las presas de rankings más bajo serán seleccionadas o no dependiendo de la abundancia de aquellas de rankings más alto (Bettinger 1991; Broughton 1994, 1997; Janetski 1997; Kelly 1995). Desde este enfoque, la intensificación se produciría entonces por una disminución de los recursos que proporcionan mayores retornos energéticos. En consecuencia, los individuos deberían explotar recursos de retorno más bajo (e.g., peces, moluscos, etc.) lo que, a su vez originaría una ampliación de la dieta. Otra estrategia que estos modelos consideran que formaría parte del desarrollo de un proceso de intensificación es la especialización, que hace referencia a la explotación de un reducido número de especies las cuales incrementarían su representación en el registro arqueológico. Asimismo, la implementación de esta estrategia puede estar acompañada por el desarrollo de nuevas técnicas y tecnologías que permitan la obtención y procesamiento más efectivo de estos recursos (Bett y Friesen 2004; Morrison 1994; Zangrando 2009).

Por otra parte, estos enfoques consideran que la intensificación no se relaciona solo con la incorporación a la dieta de una mayor diversidad de taxones de rankings más bajos, o con la especialización en la explotación de ciertos recursos sino también con la manera en la que las presas son procesadas. Desde estos modelos, a medida que disminuye la disponibilidad de las especies de ranking más alto como consecuencia de un incremento demográfico y sobreexplotación humana o debido a cambios ambientales, los individuos deben ampliar su radio de caza, aumentando la distancia y también los costos de transporte. En consecuencia, se seleccionarán para el transporte las partes esqueletarias de mayor rendimiento económico, las cuales serán utilizadas intensivamente (e.g., extracción de médula y/o grasa ósea; Burger et al. 2005; Janetski 1997; Nagaoka 2005; Prendergast et al. 2009). Asimismo, además de los cambios mencionados en la subsistencia (e.g., ampliación de la dieta, explotación más intensiva de las carcasas, etc.) estos modelos consideran que existen otros indicadores que también darían cuenta del desarrollo de este proceso como incrementos demográficos, reducción de la movilidad, cambios en el patrón de asentamiento, ocupación de ambientes considerados marginales (e.g., costa), etc. (Binford 2001; Broughton 1994, 1997; Janetski 1997).

Con relación a cuáles serían las causas que originan el proceso de intensificación, estos modelos proponen que las mismas están asociadas a factores externos, principalmente relacionados a cambios ambientales y presiones demográficas (Broughton 1994, 1997; Janetski 1997; Jones 2009; Meltzer 1999; Wolverton 2005). Con respecto a los cambios climáticos, en distintas áreas se propuso que modificaciones en la temperatura y la humedad generaron cambios en la disponibilidad de especies que afectaron directamente la subsistencia de las poblaciones, las cuales se adaptaron a ellos ampliando su dieta e intensificando el consumo de algunas especies (Jones 2009; Meltzer 1999; Wolverton 2005). Con relación a las presiones demográficas, en algunos casos se planteó que el aumento demográfico habría generado la sobreexplotación de los recursos de mayores retornos energéticos por lo que los grupos ampliaron su dieta, incluyendo especies de retornos más bajos (e.g., moluscos, peces, etc.; Broughton 1994, 1997). Asimismo, en algunas áreas se propuso que el crecimiento de la población sumado a una reducción del tamaño del área disponible, habrían sido los factores principales para el desarrollo de este proceso (Binford 2001). 
Procesos de intensificación de los recursos desde enfoques orientados ecológicamente fueron propuestos en diferentes partes del mundo. (e.g., sudoeste de Francia, grandes planicies de Norteamérica, etc.; Jones 2009; Meltzer 1999). Asimismo, en Argentina (e.g., sur de Mendoza, región del canal de Beagle, región Pampeana) también se propusieron modelos de intensificación basados en los modelos ecológicos y, fundamentalmente, en principios procedentes de la teoría del forrajeamiento óptimo (Álvarez 2014; Neme y Gil 2008; Otaola 2012, 2013; Zangrando 2009).

Los enfoques socialmente orientados, por su parte consideran que la sociedad es quien posee el rol principal en el desarrollo de este proceso. Desde esta perspectiva, la intensificación no se origina únicamente como una respuesta a factores externos, por lo que debe ser evaluada en el marco de un contexto socio-económico amplio. Según estos modelos hay varios indicadores que dan cuenta de este proceso, entre ellos: diversificación de la dieta, incremento en la complejidad económica de los sitios, mayor diferenciación intra e inter sitio, uso intensivo de los sitios, menor movilidad residencial, aumento demográfico, ocupaciones en sectores costeros, lacustres o ribereños, cambios tecnológicos, etc. (Lourandos 1983, 1997; Price y Brown 1985; Williams 1987). En algunos casos, se propuso también que el proceso de intensificación está asociado con un incremento de la complejidad de los grupos cazadores-recolectores, alta densidad poblacional, sedentarismo, tecnologías elaboradas y cambios organizacionales en aspectos sociales, económicos y rituales (Ames 1985, 1994; Price y Brown 1985; Williams 1987).

Con relación a las causas de este proceso, a diferencia de los enfoques ecológicos que consideran que los factores externos son los generadores del cambio, los modelos socialmente orientados plantean que las transformaciones están vinculadas con una reestructuración de las relaciones sociales. En este sentido, el proceso de intensificación se originaría por la presencia de redes sociales más intensivas y competitivas que generarían mayores demandas sobre la economía y la producción. En consecuencia, se utilizarían estrategias más eficientes, con la explotación de nuevas áreas y recursos y un manejo más intensivo de éstos (Bender 1981; Lourandos 1983, 1985; Price y Brown 1985; Williams 1987). Otros modelos proponen que el paisaje social también es clave en el desarrollo de este proceso (Holly 2005). En este caso, la intensificación se originaría como resultado de la coexistencia de varios grupos en un mismo ambiente. En este sentido, en áreas donde los recursos se encuentran distribuidos de manera heterogénea y son abundantes estacionalmente, los grupos responderían a la presencia de los "Otros" apropiándose de los sectores con recursos específicos e intensificando las estrategias de subsistencia. Esto se realizaría mediante la concentración de grandes fuerzas de trabajo en lugares estratégicos del paisaje para incrementar las tasas de obtención de recursos, lo que a su vez estaría acompañado por un incremento en el sedentarismo, agregación social y la producción de tecnología relacionada a la subsistencia (Holly 2005).

Modelos de intensificación desde enfoques orientados socialmente fueron propuestos para distintas áreas de Norteamérica (Holly 2005) y Australia (Lourandos 1983, 1997). En Argentina, específicamente en el área del Canal de Beagle se propuso que el incremento demográfico, producto de la coexistencia de las poblaciones locales con las procedentes de áreas vecinas pudo haber generado una competencia por los recursos y las áreas de aprovisionamiento de los mismos, dando lugar a una intensificación en la subsistencia (Zangrando 2009 y comunicación personal 2014). Asimismo, en la subregión Pampa Húmeda se utilizó esta perspectiva teórica para explicar los cambios ocurridos durante el Holoceno tardío en distintas esferas organizacionales de los grupos humanos vinculados con un proceso de complejización (González 2005; Loponte et al. 2002; Martínez 1999; Politis et al. 2001). 
Si se analizan las principales propuestas de los modelos ecológicos y los socialmente orientados se observa que son opuestas con relación a las causas (externas vs. internas) que conducirían al proceso de intensificación. Sin embargo, algunos de los indicadores que utilizan para evaluar este proceso así como sus implicancias arqueológicas están presentes en ambas perspectivas (e.g., intensidad en el uso de los sitios, establecimiento de nuevos asentamientos en áreas marginales, etc.; ver Binford 2001). Por lo tanto, se puede considerar que estos enfoques son complementarios con relación a qué indicadores utilizar para evaluar el mismo, independientemente de los factores causales (ambiente, recursos o relaciones sociales; Butler y Campbell 2004; Morrison 1994). Esto, a su vez significa que se deben evaluar en cada caso en particular las condiciones bajo las cuales se desarrolló este proceso. Se considera que este enfoque es el más apropiado para el estudio del mismo y es el que fue utilizado para analizar el proceso de intensificación en el área de transición pampeano-patagónica oriental (curso inferior del río Colorado; ver debajo).

\section{El proceso de intensificación en el área de transición pampeano-patagónica oriental}

\section{Condicionantes socio-culturales, tafonómicos y ambientales}

Antes de presentar los resultados del análisis del desarrollo de este proceso en el área de estudio es necesario realizar algunas aclaraciones. En principio, entendemos que en el desarrollo de un proceso, en este caso el de intensificación, intervienen diferentes componentes que se influyen mutuamente. Asimismo, la intensificación es vista como un proceso que depende de circunstancias históricas dadas en el contexto de organizaciones sociales particulares en un espacio y tiempo determinado. En consecuencia, la fuerza motora del cambio no descansa exclusivamente en factores externos y/o internos y tampoco depende de un único factor. La historicidad de estos procesos hace que cada caso sea particular y el desafío es poder evaluar el peso que estos factores han tenido en el surgimiento de los mismos. Es por esto que antes de avanzar en la discusión del proceso de intensificación en el área, es imprescindible mencionar las propiedades organizacionales de las sociedades cazadoras-recolectoras pampeano-patagónicas, derivadas de los estudios arqueológicos llevados a cabo hasta el momento. Para estas regiones, diversos autores han propuesto una reorganización de los sistemas culturales hacia el Holoceno tardío final (ca. 1000-250 años $\mathrm{AP}$ ). Estos cambios incluyen diversos fenómenos socio-económicos y demográficos como un crecimiento de la población, contactos inter-étnicos, redes sociales de interacción y complementariedad social en diferentes escalas (local, regional y extra regional), reducción de la movilidad, circunscripción espacial y nucleamientos demográficos, regionalización, etc. (Barrientos y Pérez 2004; Berón 2004, 2007a; Favier Dubois et al. 2009; Gómez Otero 2006; Madrid y Barrientos 2000; Mazzanti 2006; Politis 2008; Prates 2008). Estos cambios no son ajenos a los propuestos en el curso inferior del río Colorado (Flensborg 2012; Martínez 2008-2009; Stoessel 2012a) y este es el escenario en el que debe entenderse el proceso de intensificación.

Por otra parte, un factor que afecta el análisis de los procesos de intensificación es la carencia de sitios que correspondan a lapsos temporales contiguos que permitan evaluar fehacientemente los cambios ocurridos (ver apartado de discusión). La presencia de factores tafonómicos y su influencia diferencial en períodos contiguos fue resaltado en términos de entender el proceso como un todo (ver Borrero 2002). En el caso particular del curso inferior del río Colorado, los estudios geoarqueológicos y geomorfológicos realizados mostraron diferencias en la preservación del registro arqueológico y la existencia de sesgos tafonómicos 
tanto espaciales como temporales (ver discusión en Martínez y Martínez 2011). Si bien la situación es compleja, los sitios del Holoceno tardío inicial (ca.3000-1000 años AP) presentan una baja preservación de restos orgánicos, integridad y resolución arqueológicas cuando se los compara con los sitios del Holoceno tardío final (ca. 1000-250 AP), lapso para el que es propuesto el proceso de intensificación. Más allá de estos factores, que sin duda afectaron la preservación de los materiales arqueológicos, los análisis tafonómicos realizados en los conjuntos del Holoceno tardío inicial y final mostraron que los restos faunísticos fueron afectados por procesos y agentes similares (e.g., acción de raíces, meteorización, abrasión, etc.). En función de estos resultados, estos contextos son comparables entre sí y pueden ser utilizados para evaluar este proceso (ver Stoessel 2012a).

Por otro lado, otro aspecto que es necesario considerar para evaluar este tipo de procesos es la presencia, la distribución y la disponibilidad de recursos en el área. A pesar de su carácter árido-semiárido, el curso inferior del río Colorado posee una diversa y amplia base de recursos producto de su situación ecotonal. La presencia del río Colorado y su delta aportan, por un lado, diversidad de recursos (e.g., peces) y, por otro, actúan como corredores facilitando la dispersión de especies en el paisaje. Además, la existencia de un estuario promueve una alta biodiversidad y productividad. En función de los recursos que han sido importantes para la subsistencia (ver debajo), y a juzgar por el registro zooarqueológico, los ungulados (e.g., guanaco) han estado presentes en toda el área a través del Holoceno tardío. Asimismo, la naturaleza del antiguo delta del río Colorado y la ubicación y complejidad de los paleocauces indican que los recursos acuáticos fluviales estuvieron distribuidos de manera relativamente homogénea en tiempo y espacio. Por último, como se mencionó anteriormente las características del estuario se suman a este patrón de ubicuidad y diversidad de especies (Martínez 2008-2009; Martínez y Martínez 2011). Si bien no se dispone de información paleoecológica detallada, dadas estas características, la distribución areal de recursos no habría afectado la disponibilidad y acceso a las especies claves en la subsistencia, al menos en esta escala espacial de análisis.

\section{Exploración del proceso de intensificación en el curso inferior del río Colorado}

Para el curso inferior del río Colorado se propuso inicialmente un modelo de subsistencia para el Holoceno tardío a partir del estudio de conjuntos zooarqueológicos procedentes de sitios del área (Figura 1; Stoessel 2007). Este modelo planteaba que la subsistencia estuvo basada en la explotación del guanaco, complementado con el consumo del venado de las pampas y el ñandú y el aporte de recursos vegetales. Este patrón sería característico del Holoceno tardío inicial (ca. 3000-1000 años AP). Sin embargo, hacia el Holoceno tardío final (ca. 1000-250 años AP) la dieta se habría diversificado con la incorporación de especies de tamaño menor (e.g., roedores, aves y peces) y, posiblemente intensificado (e.g., ungulados $\mathrm{y}$, posiblemente vegetales; Stoessel 2007). A partir de estas tendencias, se propuso evaluar el modelo de subsistencia planteado, con énfasis en el análisis del cambio observado en la misma hacia el Holoceno tardío final (ca. 1000-250 años AP). Una de las hipótesis principales que guió este trabajo señala que durante este período se produjo una intensificación en las actividades de subsistencia en el área de estudio asociada con la diversificación de la dieta y el aprovechamiento más intensivo de algunos recursos (ungulados y vegetales, Stoessel 2012a). En función de esta hipótesis se reestructuró la estrategia de investigación, incluyendo indicadores que permitieran analizar el proceso en profundidad (ver debajo). 


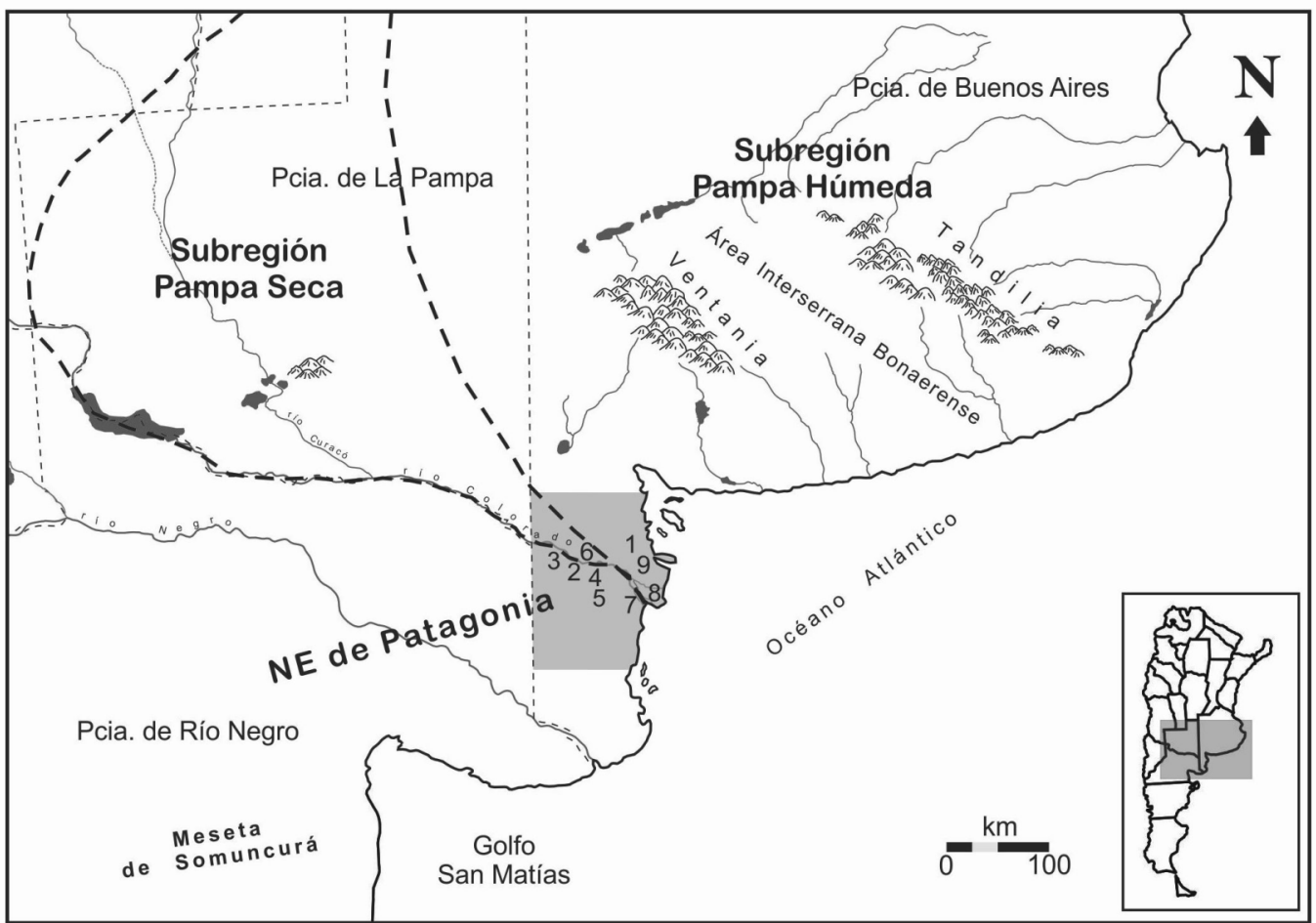

Figura 1. El curso inferior del río Colorado (sombreado) y áreas y subregiones tratadas en el texto. Referencias: 1: Loma Ruíz 1; 2: Zoko Andi 1; 3: Paso Alsina 1; 4: La Modesta; 5: Loma de los Morteros; 6: La Petrona; 7: El Tigre; 8: San Antonio; 9: La Primavera

Para evaluar el cambio en la subsistencia, se consideraron conjuntos faunísticos provenientes de sitios del Holoceno tardío inicial (La Primavera: ca. 3000-2800 años AP y Loma Ruíz 1: ca. 1900-1600 años AP; Figura 1) y del Holoceno tardío final (El Tigre: $c a$. 900-400 años AP y localidad arqueológica San Antonio: ca. 1000-800 años AP; Figura 1). Para el análisis de los restos se siguió la metodología desarrollada por enfoques procesuales (Binford 1981; Lyman 1994, entre otros). Se realizaron determinaciones y análisis cuantitativos para calcular la abundancia relativa de las distintas especies representadas (abundancia taxonómica) y para determinar la frecuencia de sus partes esqueletarias (abundancia anatómica). Asimismo, se llevaron a cabo estudios de las historias tafonómicas de los conjuntos para establecer la existencia de procesos y/o agentes que puedan haber modificado los restos faunísticos (e.g., acción de raíces, meteorización, deterioro químico, pisoteo, acción de carnívoros, roedores, etc.). A los efectos de evaluar la acción humana sobre los restos faunísticos se realizó el análisis de fracturas, huellas de corte y alteraciones térmicas (Binford 1981; Fisher 1995; Lyman 1994; para citas más específicas ver Stoessel 2012a). Además, para estudiar la intensidad en la explotación de las carcasas vinculada con el consumo de médula y grasa ósea se utilizó la metodología propuesta por Outram (2001) la cual comprende el análisis de los niveles de fragmentación y los patrones de fractura de los conjuntos. En el primer caso, los fragmentos son separados en clases de tamaños y, dentro de estas, discriminados por tipo de hueso (e.g., diáfisis, esponjoso axial, esponjoso apendicular). Las diferentes clases son cuantificadas considerando el número de fragmentos así como también su masa. Para el análisis de los patrones de fractura en 
las diáfisis, Outram (2001) desarrolló un índice de fractura fresca (IFF) considerando tres criterios: el contorno de la fractura, la textura del borde y el ángulo de la misma. Para cada uno de ellos estableció un puntaje de cero si el fragmento es consistente con una fractura fresca, de uno si posee algún rasgo de una fractura no fresca y de dos si dominan los rasgos de fractura no fresca. Para crear el índice para cada fragmento los puntajes de los tres criterios son sumados, lo cual da un índice que va entre cero y seis, donde cero indica que el espécimen es completamente consistente con una fractura fresca y seis que carece de casi todos los rasgos que posee la misma. Aquellos especímenes que poseen índices inferiores a 3 se corresponderían con fracturas originadas en estado fresco, mientras que los que superan este valor indicarían que se produjeron cuando los huesos se encontraban en estado seco. Finalmente, a los efectos de tratar con el origen de las fracturas, se promedian los valores de los tres criterios los cuales se suman y se obtiene el índice de fractura fresca del conjunto. Asimismo, para estimar la diversidad de especies consumidas en cada sitio se calculó el índice de diversidad de ShannonWeaver (Lyman 2008) y, para establecer el aporte relativo a la dieta de artiodáctilos y peces se utilizaron dos índices de abundancia (índice de artiodáctilos e índice de peces). Finalmente, si bien se utilizó esta metodología propia de orientaciones procesuales, en la interpretación de los datos y en la discusión del proceso de intensificación y sus causas se tuvieron en cuenta tanto aspectos ecológicos-ambientales como también sociales (Stoessel 2012a).

Se adoptó el concepto de intensificación mencionado al inicio de este trabajo, según el cual es un proceso por el que los grupos humanos obtienen más recursos en una unidad espacio-temporal determinada (Betts y Friesen 2004; Binford 2001; Morrison 1994). Asimismo, se consideró que la intensificación es un proceso que puede implicar diferentes estrategias (diversificación y especialización) y que los cambios en la subsistencia vinculados a su desarrollo pueden estar acompañados por modificaciones en otras esferas (e.g., tecnología, movilidad, patrones de asentamiento, etc.). En consecuencia, se plantearon y evaluaron diversos indicadores que permiten establecer la existencia del mismo. Para evaluar los cambios en la subsistencia se consideraron dos indicadores: representación de especies y fragmentación de los conjuntos faunísticos. Con respecto al primero, los análisis realizados muestran que existen diferencias en los taxones consumidos en los sitios correspondientes al Holoceno tardío inicial y final (Tabla 1). En este sentido, en aquellos ubicados cronológicamente en la parte inicial de este período, se observan pocas especies representadas y consumidas, predominando la explotación de ungulados (e.g., guanaco, venado) y aves (e.g., ñandú; Tabla 1). Durante el Holoceno tardío final, se observa un incremento significativo en la frecuencia de especies explotadas. En este sentido, los conjuntos faunísticos muestran una mayor cantidad y diversidad de taxones de tamaño menor (e.g., roedores, peces y aves), provenientes de distintos ambientes (terrestres, marinos y fluviales) con evidencias de consumo (Tabla 1; Figura 2; Alcaráz 2012; Stoessel 2012a). Si se considera el Ntaxa (categorías taxonómicas explotadas) las diferencias entre los dos momentos son claras (La Primavera: Ntaxa=3; Loma Ruíz: Ntaxa=1; San Antonio: Ntaxa= 6; El Tigre: Ntaxa=13). En este sentido, en los sitios de la parte final del Holoceno tardío se observa un incremento significativo en la frecuencia de especies explotadas (Tabla 1). Asimismo, se calculó el índice de diversidad de Shannon-Weaver para cada uno de los conjuntos faunísticos analizados (La Primavera= 0,6588; Loma Ruíz 1= 0; San Antonio=0,7441; El Tigre=0,7543), cuyos resultados también sustentan la tendencia hacia la explotación de una mayor diversidad de especies durante este período. 


\begin{tabular}{|c|c|c|c|c|c|c|c|c|}
\hline \multirow{3}{*}{ Especies } & \multicolumn{4}{|c|}{$\begin{array}{c}\text { Holoceno tardío inicial } \\
\left(3000-1000 \text { años } C^{14} A P\right)\end{array}$} & \multicolumn{4}{|c|}{$\begin{array}{l}\text { Holoceno tardío final } \\
\left(1000-250 \text { años } C^{14} \mathrm{AP}\right)\end{array}$} \\
\hline & \multicolumn{2}{|c|}{ La Primavera } & \multicolumn{2}{|c|}{ Loma Ruíz 1} & \multicolumn{2}{|c|}{ San Antonio } & \multicolumn{2}{|c|}{ El Tigre } \\
\hline & NISP & NISP\% & NISP & NISP\% & NISP & NISP\% & NISP & NISP\% \\
\hline $\begin{array}{l}\text { Lama guanicoe } \\
\text { (guanaco) }\end{array}$ & 68 & 79,07 & 55 & 100 & 37 & 1,10 & 614 & 27,58 \\
\hline $\begin{array}{l}\text { Ozotoceros } \\
\text { bezoarticus } \\
\text { (venado de las } \\
\text { pampas) }\end{array}$ & 10 & 11,63 & - & - & - & - & 37 & 1,66 \\
\hline $\begin{array}{l}\text { Rhea americana } \\
\text { (ñandú) }\end{array}$ & 8 & 9,30 & - & - & - & - & 8 & 0,35 \\
\hline $\begin{array}{l}\text { Genidens barbus } \\
\text { (bagre de mar) }\end{array}$ & - & - & - & - & 2743 & 81,44 & - & - \\
\hline $\begin{array}{l}\text { Micropogonias } \\
\text { furnieri (corvina } \\
\text { rubia) }\end{array}$ & - & - & - & - & 254 & 7,54 & - & - \\
\hline $\begin{array}{l}\text { Myliobatis sp. } \\
\text { (chucho) }\end{array}$ & - & - & - & - & 25 & 0,74 & - & - \\
\hline $\begin{array}{l}\text { Percichthys sp. } \\
\text { (perca) }\end{array}$ & - & - & - & - & 205 & 6,09 & 1361 & 61,14 \\
\hline Chondrichthyes & - & - & - & - & 29 & 0,86 & - & - \\
\hline Sciaenidae indet. & - & - & - & - & 75 & 2,23 & - & - \\
\hline Anatidae indet. & - & - & - & - & - & - & 2 & 0,08 \\
\hline $\begin{array}{l}\text { Theristicus sp. } \\
\text { (bandurria) }\end{array}$ & - & - & - & - & - & - & 1 & 0,04 \\
\hline Larus sp. (gaviota) & - & - & - & - & - & - & 2 & 0,08 \\
\hline $\begin{array}{l}\text { Nycticorax } \\
\text { nycticorax (garza } \\
\text { bruja) }\end{array}$ & & & & & & & 1 & 0,04 \\
\hline $\begin{array}{l}\text { Caviomorfo } \\
\text { pequeño tamaño }\end{array}$ & - & - & - & - & - & - & 122 & 5,48 \\
\hline $\begin{array}{l}\text { Lagostomus } \\
\text { maximus } \\
\text { (vizcacha) }\end{array}$ & - & - & - & - & - & - & 16 & 0,71 \\
\hline $\begin{array}{l}\text { Myocastor coypus } \\
\text { (coipo) }\end{array}$ & - & - & - & - & - & - & 6 & 0,26 \\
\hline $\begin{array}{l}\text { Holochilus } \\
\text { brasiliensis (rata } \\
\text { nutria) }\end{array}$ & - & - & - & - & - & - & 26 & 1,16 \\
\hline $\begin{array}{l}\text { Chaetophractus } \\
\text { villosus (peludo) }\end{array}$ & - & - & - & - & - & - & 30 & 1,34 \\
\hline Total & 86 & 100 & 55 & 100 & 3368 & 100 & 2226 & 100 \\
\hline Ntaxa & & 3 & & 1 & & 6 & & 13 \\
\hline
\end{tabular}

Tabla 1. Taxa terrestres, marinos y fluviales explotados en los sitios analizados durante el Holoceno tardío inicial y final. 


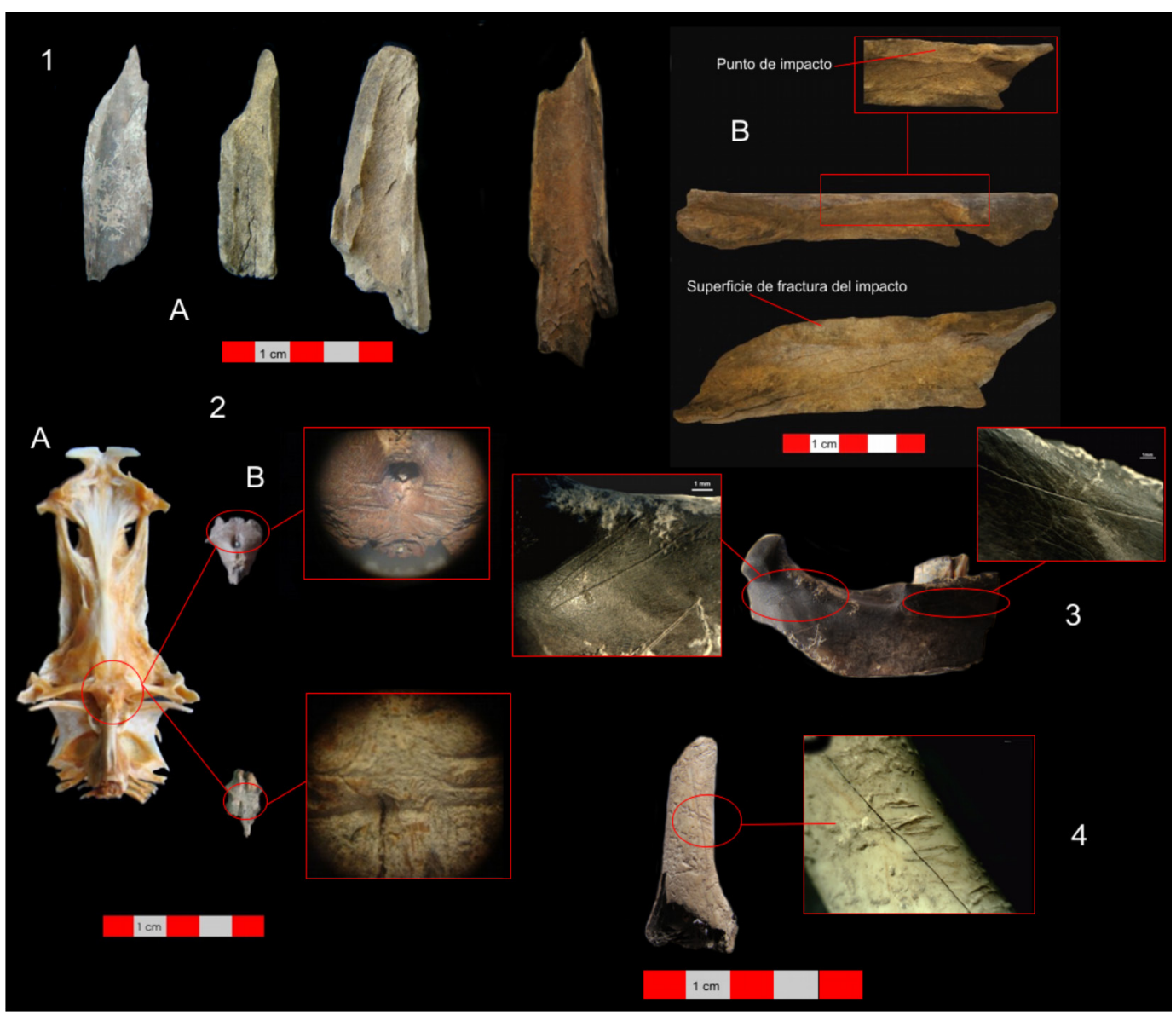

Figura 2. 1: A= Desechos de fractura helicoidal de Lama guanicoe del sitio El Tigre; $B=$ Desecho de fractura helicoidal de Lama guanicoe del sitio El Tigre, en el que se observan los rasgos tecnológicos asociados a la fractura; 2: Basioccipitales de Genidens barbus con huellas de corte provenientes de la localidad arqueológica San Antonio: $A=$ Espécimen actual; $B=$ Especímenes arqueológicos; 3: Mandíbula de Myocastor coypus con huellas de corte procedente del sitio El Tigre; 4: Húmero de Nycticorax nycticorax del sitio El Tigre con huellas de corte.

Por otro lado, si bien durante el Holoceno tardío final el registro zooarqueológico conocido indica que se habría incorporado a la dieta una mayor diversidad de taxa de tamaño menor, principalmente peces marinos y fluviales, especies de tamaño mayor como el guanaco continúan siendo explotadas (Tabla 1; Figura 2). Para evaluar la contribución relativa a la dieta de los artiodáctilos y peces se calcularon dos índices de abundancia: el índice de artiodáctilos ${ }^{1}$ y el índice de peces ${ }^{2}$. Estos índices se calculan a partir del NISP y oscilan entre 0 y 1 , donde 0 indica ausencia total y 1 dominancia absoluta. Los resultados obtenidos a partir del cálculo de los índices indican que en los sitios del Holoceno tardío inicial (La Primavera y Loma Ruíz 1) hay un dominio absoluto de los artiodáctilos (en ambos casos, índice de artiodáctilos $=1$; índice de peces $=0$ ) lo cual es esperable teniendo en cuenta que en estos conjuntos no se recuperaron prácticamente restos de peces (Figura 3). Sin embargo, en los sitios de la parte final del Holoceno tardío (San Antonio y El Tigre) se observan tendencias diferentes. En este sentido, en San Antonio la contribución de 
artiodáctilos $(0,0109)$ habría sido muy baja en comparación a los peces. En estos últimos, se obtuvo un índice muy próximo a $1(0,9890)$, lo que indicaría que los peces ocuparon un lugar central en la dieta. En El Tigre, por su parte, los resultados de los índices muestran que habría una tendencia hacia un mayor consumo de peces $(0,6764)$ en comparación a los artiodáctilos $(0,3235)$, aunque éstos habrían sido consumidos en un porcentaje mayor que en San Antonio (Figura 3). No obstante, en El Tigre el conjunto correspondiente a ungulados se encuentra altamente fragmentado. El alto grado de fracturación de los restos óseos afectó el grado de identificación de los elementos y, por lo tanto pudo influir en el cálculo del NISP de esta categoría y en el resultado de los índices. En consecuencia, podría considerarse que el aporte de los artiodáctilos podría haber sido mayor que lo que éstos indican.

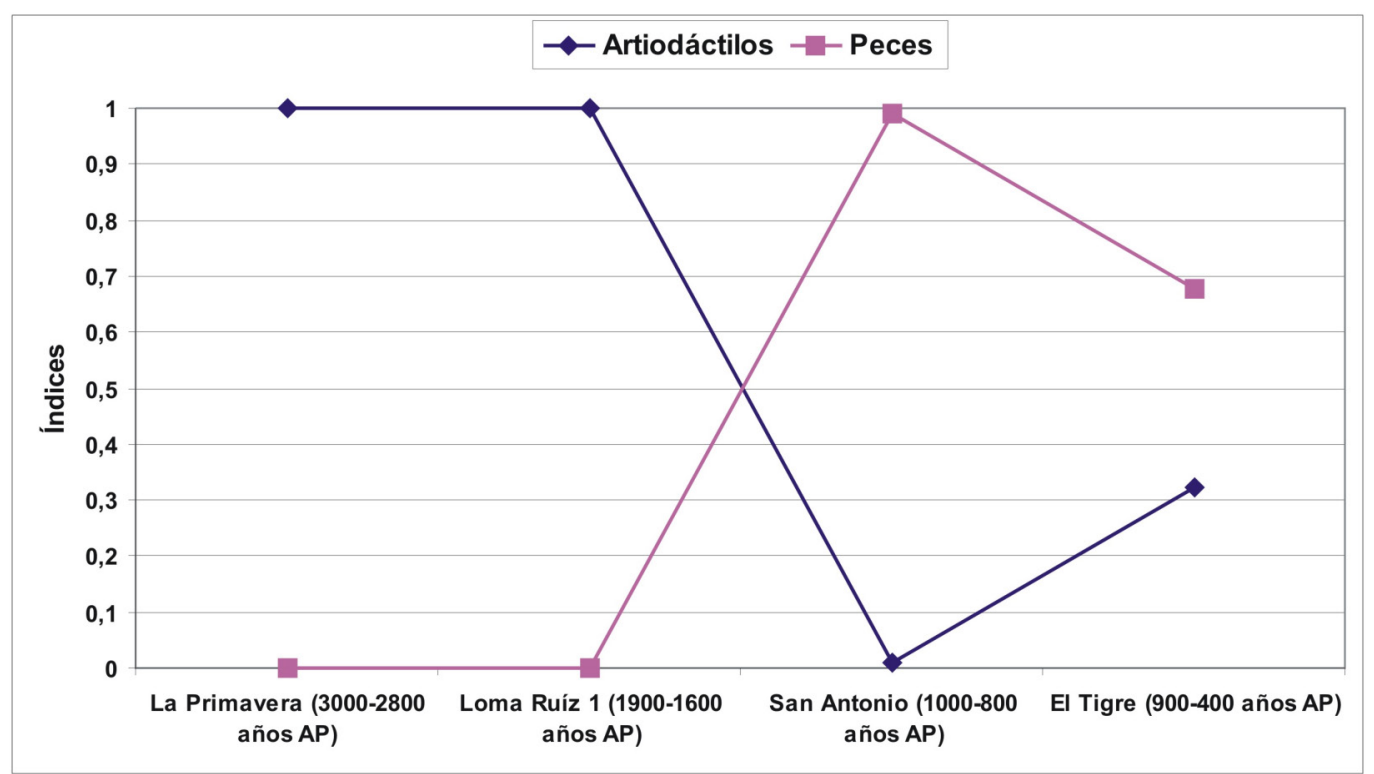

Figura 3. Comparación de los índices de artiodáctilos y peces obtenidos. Se observa la variación en la importancia de cada uno de los taxa a través del tiempo.

Con relación a la fragmentación de los conjuntos faunísticos, aquellos correspondientes a las especies de tamaño mayor se encuentran altamente fragmentados en todos los sitios analizados. No obstante, esta propiedad es más evidente en los correspondientes a la parte final del Holoceno tardío. Para evaluar el origen de esta fragmentación se siguió la metodología desarrollada por Outram (2001) vinculada con el análisis de los niveles de fragmentación y los patrones de fractura (Stoessel 2012a, 2014a). Asimismo, se llevaron a cabo análisis tafonómicos para evaluar la acción de posibles agentes y/o procesos que pudieran haber contribuido a generarla. Estos últimos mostraron que todos los conjuntos faunísticos fueron afectados por distintos procesos post-depositacionales (e.g., acción de raíces, meteorización, etc.). No obstante, la incidencia de los mismos no puede dar cuenta por sí sola del alto grado de fragmentación que presentan los restos óseos. Además, las características de los conjuntos indicarían que la acción humana fue una parte importante en su conformación. Los análisis realizados en relación con los niveles de fragmentación y los patrones de fractura indicaron que en los sitios del Holoceno tardío final (e.g., El Tigre) se habría llevado a cabo una explotación intensiva de las carcasas de ungulados (guanaco) 


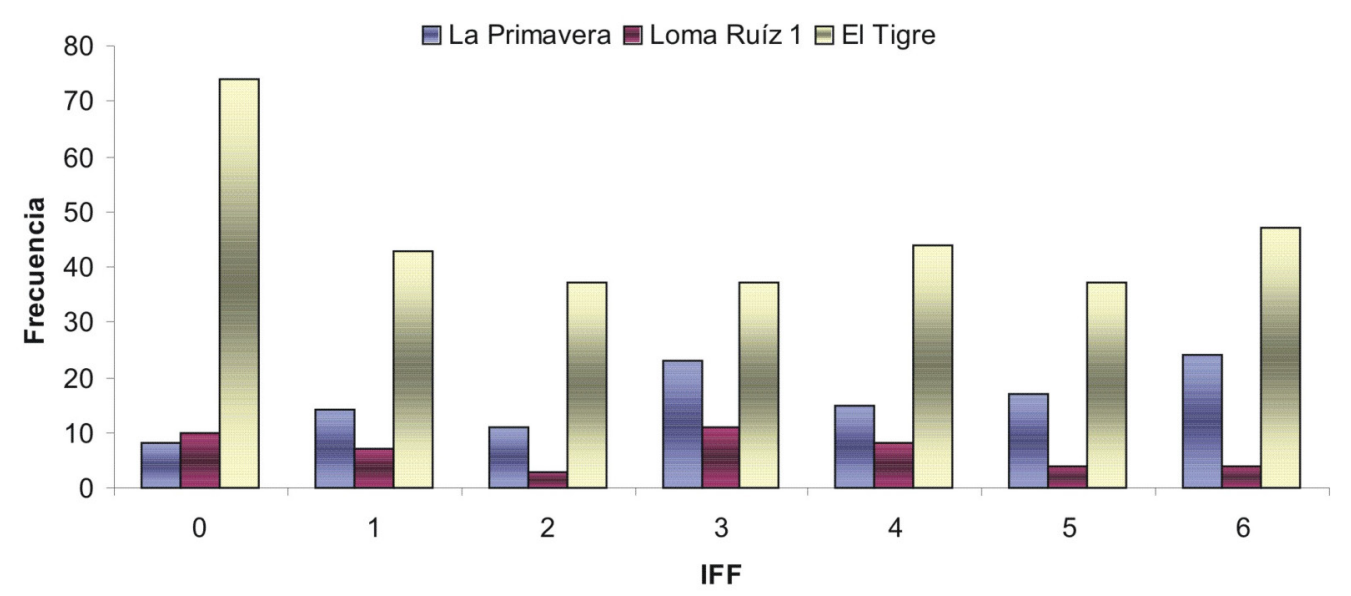

Figura 4. Índices de fractura fresca (IFF) obtenidos en los sitios analizados.

para consumo de médula y grasa ósea (Figura 4; Stoessel 2012a, 2014a). En los sitios correspondientes a la parte inicial del Holoceno tardío (e.g., Loma Ruíz 1), por su parte si bien la médula y, posiblemente la grasa ósea fueron recursos consumidos las características de los conjuntos faunísticos sugieren que su explotación no habría sido tan intensa como en las ocupaciones más tardías (Figura 4).

A partir de la información obtenida de los análisis faunísticos, se planteó un nuevo modelo de subsistencia para el área de estudio. Éste propone que durante el Holoceno tardío inicial (ca.3000-1000 años AP) la dieta se basó en la explotación del guanaco, complementado con el consumo del venado y ñandú y el aporte de recursos vegetales. Hacia el Holoceno tardío final (ca. 1000-250 años AP) se produjo una intensificación en las actividades de subsistencia asociada con una diversificación de la dieta, con la incorporación de especies de menor tamaño proveniente de distintos ambientes (terrestres, marinos y fluviales) y un aprovechamiento más intensivo del guanaco, peces y vegetales (Stoessel 2012a). El complemento de los recursos acuáticos en las dietas, muy probablemente peces (ver discusión en Martínez et al. 2009), también fue indicado por estudios de isótopos estables para el Holoceno tardío.

Por otro lado, si bien hacia la parte final del Holoceno tardío se observa un aprovechamiento más intensivo de algunos recursos (e.g., ungulados) que implicó una mayor inversión laboral (extracción de médula y grasa ósea), este patrón no sería el producto de una estrategia de especialización (sensu Betts y Friesen 2004). En este sentido, a pesar de que hay cambios tecnológicos durante este período (ver debajo) no se registra el desarrollo de nuevas tecnologías o la adecuación de algunas de éstas a los efectos de explotar recursos específicos.

Por otra parte, teniendo en cuenta que la intensificación puede implicar cambios en diferentes aspectos de la vida de los grupos humanos se analizaron otros indicadores para evaluar los mismos. Estos son: 1) Intensidad en el uso de los sitios; 2) Cambios tecnológicos y 3) Incremento en la complejidad económica de los sitios, establecimiento de nuevos asentamientos y cambios en el patrón de asentamiento. 
Con respecto a la intensidad en el uso de los sitios, se observan diferencias entre los correspondientes a las ocupaciones iniciales y finales del Holoceno tardío. En este sentido, si bien los sitios se corresponden, en general con bases residenciales en las que se habrían llevado a cabo actividades domésticas, las características de los conjuntos (e.g., baja frecuencia de restos faunísticos y escasas especies consumidas, cadenas operativas simples y presencia de las últimas etapas de las mismas, materiales de molienda de características informales, etc.) sugieren que los del Holoceno tardío inicial habrían sido producto de ocupaciones breves o efímeras. Esto es concordante con la propuesta de una mayor movilidad residencial durante este período (Martínez 2008-2009). Los sitios del Holoceno tardío final, por su parte indican ocupaciones prolongadas y/o redundancia ocupacional. Asimismo, la mayor intensidad en el uso de los sitios está evidenciada también por las características de los conjuntos líticos (e.g., mayor complejización de las cadenas operativas, mayor grado de formatización y estandarización de los instrumentos de molienda, etc.) y presencia de cerámica (ver Armentano 2012 y Martínez et al. 2011). La información procedente de las distintas líneas de análisis es consistente con una reducción en la movilidad residencial y el desarrollo de estrategias de movilidad logísticas propuestas para la parte final del Holoceno tardío (Martínez 2008-2009; Stoessel 2012a). Además, la distribución probabilística de los fechados $C^{14}$ muestra una intensa y continua señal arqueológica para los últimos ca. 1000 años AP (Martínez et al. 2013) que es interpretada como el producto de números poblacionales mayores.

Otro de los indicadores evaluados se relaciona con los cambios tecnológicos. Los estudios llevados a cabo en los conjuntos líticos muestran que durante todo el Holoceno existió una base tecnológica común que se reorganiza hacia la parte final de este período (Armentano 2012; Martínez 2008-2009). En este sentido, los conjuntos líticos de los sitios correspondientes al Holoceno tardío final presentan una mayor densidad artefactual y se registra una mayor estandarización de los instrumentos formales (raspadores y puntas de proyectil triangulares apedunculadas pequeñas), cuya producción implicó la utilización de materias primas de mejor calidad. Asimismo, los artefactos de molienda muestran un mayor grado de formatización, lo que sugiere una alta inversión de tiempo y esfuerzo en su confección (Armentano 2012; Martínez 2008-2009). Algunos de los cambios tecnológicos observados en los conjuntos correspondientes al Holoceno tardío final podrían estar vinculados con los observados en la explotación de ciertos recursos, como es el caso de los vegetales. Además, la estandarización que presentan las puntas de proyectil triangulares apedunculadas pequeñas podría estar asociada a cambios en los sistemas de armas o a una mayor intensidad en el uso de algunos de ellos (e.g., arco y flecha) mas acordes a la caza de fauna menor (e.g., aves; Armentano 2012; Martínez 2008-2009).

Por otra parte, el uso de materias primas a través del Holoceno Tardío inicial y final ha sufrido cambios. Para el primero de los lapsos, la proveniencia de las materias primas incluyó rocas alóctonas de sectores localizados al Norte (e.g., cuarcitas; sistemas serranos de Tandilia y Ventania), al Oeste (e.g., obsidianas; Cerro Huenul) y al Sur (posiblemente calcedonias traslúcidas; Meseta de Somuncurá). Para el segundo de los lapsos, la información indica ausencia de cuarcitas de Tandilia y escasa presencia de metacuarcita de Ventania en contraposición a una frecuencia mayor de calcedonia traslúcida. En función de estos resultados, Armentano (2012) propone una disminución de los contactos con individuos y/o grupos situados en las áreas ubicadas al norte (provincia de Buenos Aires) y al oeste (provincia de Mendoza). A diferencia del Holoceno tardío inicial, donde se registra una importante variabilidad de grupos tipológicos, para la parte final del Holoceno la 
producción artefactual se concentra en dos clases de instrumentos, las puntas de proyectil y los raspadores, que se confeccionan mayoritariamente en materias primas areales o locales (Armentano 2012). Esta declinación en el acceso y/o en el intercambio de materias primas provenientes de otras áreas y/o regiones, así como la mayor explotación de rocas locales para tipos particulares de artefactos podría estar respondiendo a un proceso de regionalización creciente e incrementos en la territorialidad (Martínez 2010).

El tercer indicador evaluado se relaciona con el incremento en la complejidad económica de los sitios, establecimiento de nuevos asentamientos y cambios en el patrón de asentamiento. En principio, durante la parte final del Holoceno tardío se observa una mayor complejidad económica con respecto a las ocupaciones más tempranas. Durante este período, se amplía la base de recursos con la incorporación de especies provenientes de diferentes ambientes (terrestres, marinos y fluviales). Estos cambios en la subsistencia podrían estar vinculados con la ocupación de otros sectores del espacio, algunos de ellos vinculados a cuerpos de agua (e.g., El Tigre). Por otro lado, las ocupaciones que se registran en la costa atlántica para el período (localidad arqueológica San Antonio) corresponden a ocupaciones estacionales, orientadas a la explotación de recursos marinos, especialmente peces (Martínez et al. 2010; Stoessel 2010, 2012a y 2012b).

Por otra parte, durante el Holoceno tardío final se observa una mayor variabilidad intra e inter sitio, sobre todo en los sitios con entierros humanos. En este sentido, durante la parte inicial del Holoceno tardío los entierros, exclusivamente primarios, se llevaron a cabo en aquellos lugares donde también se realizaban tareas domésticas (sitio La Primavera). En el Holoceno tardío final, si bien esta práctica continúa, se registran sitios con inhumaciones primarias y secundarias (sitio La Petrona), así como áreas exclusivas de inhumación compuestas únicamente por entierros secundarios (e.g., sitio Paso Alsina 1; Martínez et al. 2012).

En síntesis, durante el Holoceno tardío final ciertos sectores del espacio fueron ocupados por períodos más extensos o bien, redundantemente ocupados. Esto podría vincularse con asentamientos más estables y economías más intensivas. Además, la presencia de sitios de actividades específicas (e.g., Paso Alsina 1) y otros con ocupaciones estacionales (e.g., localidad San Antonio) sugiere la existencia de un componente logístico en las estrategias de movilidad de los grupos (Martínez 2008-2009). Finalmente, los diversos indicadores evaluados, muestran que los cambios ocurridos en la subsistencia hacia la parte final del Holoceno tardío estuvieron acompañados por modificaciones en otros aspectos, que se evidencian en un uso más intensivo de los sitios y cambios en el patrón de asentamiento y la movilidad, modificaciones en la tecnología y en las prácticas mortuorias (Stoessel 2012a).

\section{Causas}

Para la evaluación de las causas del desarrollo de este proceso en el área de estudio, considerando el enfoque adoptado, se analizó la incidencia de factores externos e internos. Con respecto a los primeros, se evaluó la posible existencia de cambios ambientales y crecimiento demográfico. Con relación a los cambios ambientales, dos eventos importantes como la Anomalía Climática Medieval (1200-800 años AP) y la Pequeña Edad de Hielo (450-200 años AP) han sido propuestos para algunas áreas del Hemisferio sur durante el Holoceno tardío. Las consecuencias de estos eventos (en particular la ACM) fueron variables en la región patagónica. En este sentido, Agosta et al. (2005) proponen que existiría un 
patrón bipolar, según el cual las condiciones en el norte de Patagonia serían secas y cálidas mientras que en el sur éstas serían frías y húmedas. Schäbitz $(1994,2003)$, por su parte señala que durante este momento en el extremo noreste de Patagonia predominaron condiciones semiáridas, con un incremento en la frecuencia de lluvias, a diferencia de lo que ocurriría en el centro-oeste de esta región donde se habría incrementado la aridez. Sin embargo, no hay datos generados localmente en el noreste de Patagonia que muestren la existencia de este evento, como sí sucede en otras áreas de esta región (e.g., cuencas de los lagos Salitroso/Posadas, lago Cardiel y Potrok Aike; Goñi 2010; Morales et al. 2009). No obstante, en algunos sitios del curso inferior del río Colorado cuyas ocupaciones se corresponderían cronológicamente con la Anomalía Climática Medieval se han recuperado restos de especies que no se encuentran actualmente en el área ya que son propias de ambientes más cálidos y húmedos (e.g., Holochilus brasiliensis, Ceratophrys sp.; Stoessel et al. 2008).

Por otra parte, con respecto a las especies presentes en el área, no hay evidencias de que un cambio climático haya provocado una reducción en las poblaciones de los taxones de tamaño mayor como los guanacos o cambios en su disponibilidad y/o en la accesibilidad a estos recursos. En síntesis, con la información disponible actualmente no se puede proponer la existencia de un evento específico (e.g., Anomalía Climática Medieval) en el área de estudio que pueda haber producido reorganizaciones socio-demográficas. Aunque sin dudas el ambiente y sus fluctuaciones jugaron un rol importante en estos procesos, de haber existido los cambios climáticos mencionados, éstos no habrían tenido un efecto importante sobre los recursos y sobre las estrategias de subsistencia de los grupos humanos. Se debe considerar, además que la naturaleza ecotonal del área, sumado a la presencia del río Colorado y su cercanía a la costa atlántica pudo haber amortiguado los efectos asociados a este fenómeno.

Con respecto a los incrementos poblacionales, varios autores propusieron la existencia de aumentos en la densidad demográfica en diferentes áreas de la región Pampeana (e.g., Loponte 2008; Martínez y Gutiérrez 2004; Politis 2008; Quintana y Mazzanti 2001) y Norpatagonia (e.g., Barrientos y Gordón 2004; Barrientos y Pérez 2004; Gordón 2011) durante el Holoceno tardío. Asimismo, para el área de estudio se planteó que el incremento en la intensidad de la señal arqueológica hacia el Holoceno tardío final podría vincularse con aumentos en la densidad de población (Martínez 2008-2009; Martínez et al. 2013). Estos cambios pudieron haber influido en aquellos observados en los patrones de asentamiento (e.g., ocupaciones prolongadas y/o redundancia ocupacional), en la movilidad (e.g., reducción de la movilidad residencial, desarrollo de estrategias de movilidad logística) y en la subsistencia. En este último caso, la incorporación a la dieta de una mayor variedad de especies de tamaño menor como parte de un proceso de diversificación pudo ser una elección adecuada para una población creciente y con menor movilidad, teniendo en cuenta las características de estos taxones (e.g., localización predecible en el espacio, facilidad de captura, abundancia, ciclos reproductivos cortos, etc.). Estos cambios también podrían contribuir a explicar la intensificación en la explotación de alguna de ellas (e.g., peces) así como de las que proporcionan retornos energéticos más altos (e.g., guanaco; Stoessel 2012a).

Con relación a la existencia de transformaciones vinculadas con una reestructuración de las relaciones sociales, se propuso que el curso inferior del río Colorado formó parte de una frontera blanda durante el Holoceno tardío final (Gordón 2011; Martínez 2008-2009). En este sentido, la existencia de aspectos comunes con otras áreas, evidenciados en diferentes componentes de la cultura material sugiere que el área de estudio habría sido parte de un territorio dinámico en el que se produjeron diferentes situaciones de contacto entre grupos 
con identidades distintas las cuales se materializaron en el registro arqueológico (Martínez 2008-2009; Stoessel 2012a). El empleo intensivo de la modalidad secundaria como estrategia de entierro, la fuerte manipulación y traslado de los cuerpos y la aparición de las áreas formales de entierro indicaría nuevas relaciones entre grupos y demarcación territorial (Martínez et al. 2012). Este contexto de interacción pudo haber contribuido a generar una intensificación en las relaciones sociales y, de esta manera al desarrollo de estrategias más eficientes y economías más intensivas. Estos factores también habrían contribuido en los cambios ocurridos en la subsistencia (ver debajo).

En síntesis, el proceso de intensificación se habría desarrollado en el área de estudio como consecuencia de una conjunción de factores demográficos y sociales. El aumento en la densidad poblacional junto con la presencia de redes sociales más intensivas producto de dinámicas poblacionales fluidas entre áreas vecinas habrían sido los principales factores que promovieron el cambio en el sistema de subsistencia y en otras esferas hacia la parte final del Holoceno tardío. Asimismo, si bien no hay evidencias de que un cambio ambiental haya "gatillado" estas modificaciones, no se descarta que el ambiente y sus fluctuaciones sean variables que influyeron en las estrategias de los grupos humanos (Stoessel 2012a). En términos generales, la evidencia presentada para el área de estudio se condice con el modelo propuesto por Binford (2001), quien señala que la disminución en el tamaño del área disponible, junto con aumento demográfico y la disminución en la movilidad, en grupos que se encuentran circunscriptos espacialmente, serían variables claves en el desarrollo de un proceso de intensificación. En este sentido, estos factores generarían una dependencia de las especies de mayor tamaño y una ampliación de la dieta, con el consumo de recursos vegetales y acuáticos. Asimismo, se producirían cambios en los patrones de asentamiento, con ocupaciones en sectores considerados marginales (e.g., costa; Binford 2001). La evidencia proveniente de los sitios del curso inferior del río Colorado sustenta la idea de que un proceso con características similares se desarrolló en el área de estudio hacia la parte final del Holoceno tardío.

El proceso de intensificación en escalas espaciales regionales: propuestas y perspectivas.

En áreas lindantes al curso inferior del río Colorado se propusieron cambios similares a los planteados para el área de estudio durante el Holoceno tardío. En este sentido, en distintas áreas de la subregión Pampa Húmeda se planteó la existencia de procesos de intensificación hacia el Holoceno tardío (González 2005; Loponte et al. 2002; Martínez 1999; Politis et al. 2001; Quintana y Mazzanti 2001). Asimismo, a partir de la información generada se propusieron modelos generales de síntesis que plantean para este período la existencia de economías areales de diversificación e intensificación en la explotación de recursos (Martínez y Gutiérrez 2004). Particularmente para el área Interserrana (Figura 1), Martínez (1999) propuso para el Holoceno tardío (desde ca. 3000 años AP) una litificación del paisaje que estaría asociada al desarrollo de un proceso de intensificación. Asimismo, señala una serie de cambios que estarían vinculados al desarrollo de este proceso: a) aumento en la densidad de población y la demografía; b) incorporación de recursos de bajos niveles tróficos y ampliaciones en el espectro de especies explotadas; c) cambios tecnológicos, innovaciones tecnológicas (cerámica, arco y flecha); d) cambios en el patrón de asentamiento a través de residencias más prolongadas y estables y demarcación territorial; e) reducción de la movilidad residencial y el desarrollo de estrategias de movilidad logísticas; f) mayor inversión de tiempo en aspectos no vinculados a la subsistencia (e.g., arte, ajuares, entierros, etc.); g) surgimiento de relaciones sociales jerárquicas, sentido de propiedad, división del 
trabajo, etc. (Martínez 1999; ver también Politis et al. 2001). Con respecto a las causas de este proceso, este autor considera que el desarrollo del mismo no depende de una única variable sino de varias que pueden intervenir en mayor o menor grado en su surgimiento, aunque esto no significa que deban estar presentes necesariamente todos los factores asociados generalmente a su surgimiento. Para el área Interserrana, plantea que este proceso se habría evidenciado en tres aspectos: 1) Intensificación de la producción; 2) Intensificación en el uso de lugares específicos del paisaje y 3) Intensificación en las relaciones sociales. En este sentido, propone que la mayor densidad de población, las innovaciones (e.g., arco y flecha y cerámica) y reorganizaciones tecnológicas (e.g., litificación del paisaje), el mayor uso de materiales relacionados a la molienda, los cambios en la subsistencia (mayor dependencia de los vegetales) y en el sistema de asentamiento (e.g., reocupación de lugares) habrían generado las nuevas condiciones ambientales y sociales que formaron parte de un proceso creciente de complejidad que incluiría un proceso de intensificación (Martínez 1999; Martínez y Mackie 2003-2004; Politis et al. 2001).

Siguiendo la propuesta de Martínez (1999), Politis et al. (2001) consideran que la adopción de la cerámica en el área durante el Holoceno tardío estuvo relacionada con la intensificación en la producción. Sin embargo, la alfarería no estaría vinculada solo a la subsistencia ya que su decoración habría tenido un importante contenido simbólico y habría sido utilizada para transmitir información y expresar vínculos, en un contexto de intensificación de las relaciones sociales y de creciente complejización de las sociedades cazadoras-recolectoras durante este período (Politis et al. 2001).

Para la porción centro de la subregión Pampa Húmeda, Messineo (2008) propuso, para la parte inicial del Holoceno tardío (3500-1700 años AP), la existencia de una mayor diversificación en la representación de especies debida a su utilización en la dieta y en eventos rituales. Sin embargo, este autor sostiene que, analizando la importancia diferencial de las especies en la dieta, no es posible defender la existencia de un proceso de intensificación Esto se debe a la falta de especificidad funcional de los sitios, a la ausencia de una cuantificación detallada sobre las unidades anatómicas y a la falta de una medición del grado en que las especies fueron explotadas a partir de indicadores como la fragmentación y marcas de faenamiento.

Recientemente, Álvarez (2014) analizó la evidencia faunística proveniente de sitios del área Interserrana para evaluar la existencia de un proceso de intensificación en la explotación de recursos durante el Holoceno tardío. Desde un enfoque ecológico, considerando a la intensificación como un incremento en la productividad por unidad de tierra con la consecuente declinación en la foraging efficiency, evaluó una serie de indicadores para determinar la existencia del mismo: 1) cambios en el perfil de partes esqueletarias de ungulados; 2) cambios en los indicadores de procesamiento; 3) cambios en las frecuencias de las especies grandes y pequeñas y 4) cambios en la diversidad faunística y en la riqueza taxonómica. Los resultados obtenidos del análisis de estas variables no sustentarían la existencia de un proceso de intensificación en el área sino, por el contrario sugerirían una continuidad en las estrategias de subsistencia desde momentos anteriores (Álvarez 2014). En este sentido, señala que si bien durante el Holoceno tardío se observa un mayor énfasis en el consumo de guanaco, éste no estaría vinculado con el desarrollo de un proceso de intensificación sino con variaciones en la disponibilidad local de este recurso. Finalmente, sugiere que si bien la evidencia del área Interserrana muestra cambios hacia el Holoceno tardío en la organización social de los grupos, una intensificación en las relaciones sociales 
(ver también Messineo 2008) y la introducción de nuevas tecnologías, éstos no fueron acompañados por modificaciones en la explotación de recursos. Con respecto a la demografía, Álvarez (2014) sugiere que no habrían existido cambios demográficos importantes en el área o que, de haber ocurrido éstos no habrían impactado negativamente en las especies presentes.

Por otro lado, para la subregión Pampa Seca (Figura 1) Berón et al. (2009) señalan que hacia la parte final del Holoceno tardío se produjeron modificaciones en la subsistencia vinculadas a una diversificación de la dieta y una intensificación en la explotación de algunas especies como guanaco, ñandú, cérvidos y dasipódidos. Asimismo, la evidencia indirecta proveniente del registro artefactual de este período sugiere también una intensificación en el consumo de recursos vegetales. Esta propuesta se basa fundamentalmente en los trabajos realizados en la localidad arqueológica Tapera Moreira, cuya evidencia es útil para evaluar el desarrollo de este tipo de procesos dado que representa el uso del espacio de manera recurrente durante el período $c a$. 4500-500 años AP. Se propuso que los cambios en la localidad comienzan a observarse a partir de la segunda ocupación (ca. 1940-1800 años $\mathrm{AP}$ ) y que están evidenciados por un mayor aprovechamiento de especies de tamaño menor (e.g., aves, roedores y bivalvos fluviales) y una explotación más intensiva de algunos taxones (e.g., consumo de médula de ungulados). Berón (2013) menciona que los cambios en la dieta estuvieron acompañados por un crecimiento demográfico, la incorporación de la cerámica y la fabricación de elementos de carácter simbólico. Además, durante este momento se habrían incrementado los conflictos y los niveles de violencia como consecuencia de la concentración de los individuos en los principales parches de recursos, principalmente en torno a un recurso crítico como es el agua en esta región. En este sentido, las condiciones ambientales del período (e.g., baja humedad, sequías marcadas), sumado al aumento demográfico habrían generado una reducción de la movilidad residencial y una mayor permanencia de las poblaciones en estos espacios (Berón 2007a). Este contexto, coincide también con una intensificación en las relaciones inter grupales que sugieren la existencia de una complementariedad social entre las poblaciones (Berón 2007b, 2013; Berón et al. 2009).

Por otra parte, en Norpatagonia oriental, en el área de la costa del Golfo San Matías (Figura 1), también se plantearon cambios en la subsistencia que fueron relacionados con la intensificación y diversificación de la dieta. Sin embargo, en este caso se produjeron en diferentes momentos del Holoceno tardío. En este sentido, la intensificación se habría desarrollado durante la parte inicial de este período y habría estado basada en la explotación de recursos marinos (especialmente mamíferos), lo que fue vinculado con la mayor productividad que tienen en regiones semiáridas los ambientes litorales en comparación a los sectores continentales. Hacia la parte final del Holoceno tardío, la dieta se habría diversificado con la explotación de ungulados, rheidos y mamíferos pequeños (Favier Dubois et al. 2006, 2009; Scartascini et al. 2009). En este caso, Favier Dubois et al. (2009) consideran a la diversificación como otra estrategia de intensificación dado que genera un aumento en la capacidad de carga del ambiente y reduce los riesgos que implica la explotación de pocos recursos en ambientes donde éstos son inestables. Su propuesta tiene sustento en los resultados de los estudios de isótopos estables en restos óseos humanos los cuales indican dietas predominantemente marinas entre $c a$. 3100-2200 AP y dietas mixtas a terrestres entre $c a$. 1500-420 AP (Favier Dubois et al. 2009). Asimismo, el registro zooarqueológico del Holoceno tardío inicial está compuesto mayormente por restos de peces y de lobo marino, mientras que en los conjuntos faunísticos del Holoceno tardío final si bien estos recursos continúan estando presentes se suman otros como guanaco, rheidos y pequeños mamíferos como armadillos. Asimismo, señalan que la incorporación de nuevas tecnologías (e.g., cerámica, 
puntas de proyectil pequeñas) permitiría una explotación más efectiva de los recursos. Estos cambios acompañarían a un crecimiento demográfico que llevó a una ocupación efectiva del litoral costero (Favier Dubois et al. 2006, 2009).

\section{Discusión y consideraciones finales}

En sus comienzos, el concepto de intensificación estuvo fuertemente relacionado con las prácticas agrícolas (Boserup 1965, ver también Leach 1999 y Morrison 1994). La utilización del concepto ha sido cuestionada por varias razones. En primer lugar, el concepto original de Boserup fue sostenido sobre las bases de asumir la existencia de la presión poblacional. En segundo lugar, dados sus orígenes en teorías económicas, el concepto ha sido preferentemente utilizado en función de medir productividad, producción y los incrementos en los costos de trabajo referidos a especies específicas (e.g., peces). En tercer lugar, la identificación de este proceso exige una comparación cronológica, en períodos sucesivos, de la carga de trabajo y la productividad. En cuarto lugar, la intensificación ha sido considerada generalmente como un proceso unilineal y progresivo (ver discusión en Ames 1994; Bender 1978: 205; Leach 1999; Lourandos 1985: 389-390; Morrison 1994: 146). Entre otras implicaciones, esta última consideración ha llevado a proponer una relación unívoca entre intensificación y complejidad social, relación que debe, en todo caso, analizarse discutiendo casos particulares (ver discusión en Zangrando 2009). Debido a algunas de estas cuestiones se ha propuesto un uso excesivo del concepto y se sugirió el abandono y/o reemplazo del mismo (ver Leach 1999). Es probable que las visiones básicamente economicistas y teleológicas originalmente vinculadas al concepto así lo sugieran, pero una visión más amplia del mismo, como la discutida precedentemente, ha demostrado ser de suma utilidad (ver debajo).

Respecto de la configuración de las subsistencias regionales, es posible que la selección de las presas y la amplitud de dieta den cuenta de la disponibilidad faunística en términos biogeográficos y que la estructura del registro arqueofaunístico no se deba necesariamente a un proceso de intensificación para el Holoceno tardío de algunas regiones (e.g., Otaola 2013). También es razonable argumentar que las subsistencias areales y/o regionales (e.g., región Pampeana) adquirieron su configuración debido a cambios en la disponibilidad local de recursos específicos (Álvarez 2014). No obstante, si bien es cierto que la estructura y configuración de los recursos a través del paisaje juegan un rol importante en la diversidad y accesibilidad de especies potencialmente consumidas y en la forma e intensidad con las que son explotadas, la explicación no se agota considerando únicamente estas condiciones. Como ha sido expresado en apartados anteriores, a los efectos de evaluar procesos de intensificación, son necesarias perspectivas más inclusivas donde variables ecológicas y socio-demográficas interactúen entre sí. En este sentido, las condiciones planteadas para el Holoceno tardío del área de estudio sugieren un escenario denso-dependiente que incluye una mayor demografía, territorialidad, niveles de agregación y circunscripción espacial (Barrientos y Pérez 2004; Gordón 2011; Martínez 2008-2009). Esto produciría una regulación en el acceso a los recursos a través de protocolos territoriales dando lugar a relaciones sociales más intensas y competitivas. Una de las consecuencias esperadas para estas dinámicas producidas por estas formaciones sociales "relativamente cerradas" (Gamble 1986: 322; 331; Lourandos 1997: 28), pero no por eso menos dinámicas y fluidas, es la existencia de procesos de intensificación ligados a una regionalización (David y Lourandos 1998, 1999; González Morales 1991; Lourandos 1997). En consecuencia, se plantea que las economías areales de diversificación e intensificación (Martínez y Gutiérrez 2004), definidas en escalas regionales, no necesariamente surgen debido a la estructuración, distribución y disponibilidad "natural" 
de los recursos en un ambiente. Dichas economías se gestan en función del ambiente y de las características sociales y demográficas propias del período considerado. Por ejemplo, los ambientes y la distribución natural de los recursos en Tandilia oriental y en el curso inferior del río Colorado son absolutamente disímiles pero, sin embargo las estrategias de subsistencia desarrolladas por estos grupos indígenas para los últimos 1000 años AP (e.g., aprovechamiento intenso de carcasas de ungulados, alta fragmentación ósea, aumento de especies pequeñas de varias categorías, incorporación de especies presentes pero no explotadas en momentos previos, complejidad en las formas de procesamiento de especies pequeñas, entre otros) poseen importantes similitudes (ver Quintana y Mazzanti en este volumen). Esto indicaría, en consecuencia, estrategias de subsistencia similares operando en simultáneo en función de contextos socio-demográficos específicos, independientemente de las imposiciones ambientales.

El concepto de intensificación mantiene su vigencia y se ha instalado en las agendas de algunas regiones y áreas. En el caso de la subregión Pampa Húmeda las formulaciones iniciales del proceso para el área Interserrana (Martínez 1999, Politis et al. 2001) fueron seguidas por aproximaciones metodológicas más fuertes y sensibles para captar este proceso (Álvarez 2014; Messineo 2008). Para el área de Tandilia, el concepto también sigue vigente y se observa una preocupación a través del tiempo por el empleo de vías metodológicas que permitan analizar el proceso (Quintana y Mazzanti 2001 y en este volumen). En la depresión del Salado (González 2005) y en el área Norte (Loponte et al. 2002) se utilizaron diversos indicadores para evaluar el desarrollo de este proceso y su vinculación con escenarios de complejidad en sociedades cazadoras-recolectoras. Para la subregión Pampa Seca el proceso fue propuesto y son necesarios nuevos sitios y análisis para indagar en el mismo. En la transición pampeano-patagónica oriental el estudio de este proceso constituyó y constituye un eje vertebrador de las investigaciones donde la conceptualización del mismo sufrió cambios a través del tiempo (Stoessel 2007, 2012a). Recientemente, se registraron sitios multicomponentes que incluyen ambos períodos del Holoceno tardío (Zoko Andi 1; Martínez et al. 2014) y otros con cronologías de |wl Holoceno medio (Carden y Martínez 2014; Stoessel 2014b), con presencia de materiales faunísticos, que permitirán re-evaluar el modelo aquí propuesto.

En suma, el proceso y su discusión se mantuvo vigente en los proyectos de investigación y ha demostrado ser de suma utilidad, no solo para abordar la complejidad de las subsistencias en diferentes áreas sino para afinar y dirigir de forma más adecuada cuestiones metodológicas, sobre todo ligadas al registro arqueofaunístico (Alcaráz 2012; Álvarez 2014; Martínez y Gutiérrez 2004; Quintana y Mazzanti 2010 y este volumen; Stoessel 2012a; entre otros). La instalación del concepto y sus implicaciones arqueológicas en las agendas también llevó a un análisis profundo y a la especificación de los marcos teóricos desde los cuales se analiza, logrando una mayor madurez en la discusión de este proceso desde sus formulaciones iniciales.

Agradecimientos: A los Dres. Matías Medina y Luciano Prates por su gentil invitación para participar de este volumen. A Pancho Zangrando, Gustavo Flensborg, María Clara Alvarez y Ana Paula Alcaráz por la lectura del manuscrito, sus aportes y comentarios. A Pablo Bayala por su ayuda con el material gráfico. Al INCUAPA-CONICET-UNICEN por las facilidades brindadas. 
Notas

1 Índice de artiodáctilos: $\Sigma$ NISP artiodáctilos / $\Sigma$ (NISP artiodáctilos + NISP peces).

2 Índice de peces: $\Sigma$ NISP peces $/ \Sigma$ (NISP peces + NISP artiodáctilos).

\section{Bibliografía citada:}

Agosta, E. A., C. Favier Dubois y R. H. Campagnucci

2005 Anomalías climáticas en la Patagonia durante el Calentamiento Vikingo y la Pequeña Edad de Hielo. Trabajo publicado en el Libro del Congrement. Buenos Aires.

Alcaráz, A.P.

2012 Análisis zooarqueológico y tafonómico de restos óseos de pequeños vertebrados de sitios del curso inferior del río Colorado (pcia. de Buenos Aires) durante el Holoceno tardío. Aportes para el conocimiento de la subsistencia y procesos de formación. Tesis de Licenciatura inédita. Facultad de Ciencias Sociales, UNCPBA, Olavarría.

Álvarez, M.C.

2014 Subsistence patterns during the Holoceno in the Interserrana area (Pampean region, Argentina): Evaluating intensification in resource exploitation. Journal of Anthropological Archaeology 34: 54-65.

Ames, K.

1985 Hierarchies, stress and logistical strategies among hunter-gatherers in nortwestern North America. Prehistoric Hunter-Gatherers: the Emergence of Cultural Complexity (ed. por T. Price y J. Brown), pp.155-180. Academic Press.

1994 The Northwest Coast: Complex Hunter-Gatherers, Ecology, and Social Evolution. Annual Review of Anthropology 23: 209-229.

Armentano, G.

2012 Arqueología del curso inferior del Río Colorado. Estudio tecnológico de las colecciones líticas de Norpatagonia Oriental durante el Holoceno tardío. Departamentos de Villarino y Patagones, Provincia de Buenos Aires, Argentina. Tesis Doctoral inédita. Universidad Nacional del Centro de la Provincia de Buenos Aires y Université de Paris Ouest Nanterre-la défense. France arts, Lettres et Sciences Humaines. École doctoral: Milieux, cultures et sociétés du passé et du présent.

Barrientos, G. y F. Gordón

2004 Explorando la relación entre nucleamiento poblacional y violencia interpersonal durante el Holoceno tardío en el noreste de Patagonia (República Argentina). Magallania 32: 53-69.

Barrientos, G. y S.I. Pérez

2004 La expansión y dispersión de poblaciones del norte de Patagonia durante el Holoceno tardío: evidencia arqueológica y modelo explicativo. Contra viento y marea. Arqueología de Patagonia (ed. por M.T. Civalero, P.M. Fernández y A.G. Guraieb), pp. 179-195. Instituto de Antropología y Pensamiento Latinoamericano, Buenos Aires.

Bender, B.

1978 Gatherer-hunter to farmer: a social perspective. World Archaeology 10: 204-222. 
1981 Gatherer-hunter intensification. Economic Archaeology (ed. por A. Sheridan y G. Bailey), pp. 149-157. BAR International Series 96.

Berón, M.A.

2004 Dinámica poblacional y estrategias de subsistencia de poblaciones prehispánicas de la cuenca Atuel-Salado-Chadileuvú-Curacó, Provincia de La Pampa. Tesis Doctoral inédita. Universidad de Buenos Aires, Buenos Aires.

2007a Integración de evidencias para evaluar dinámica y circulación de poblaciones en las fronteras del río Colorado. Arqueología de Fuego-Patagonia. Levantando piedras, desenterrando huesos... y develando arcanos (ed. por F. Morello, M. Martinic, A. Prieto y G. Bahamonde), pp. 173-188. Ediciones CEQUA, Punta Arenas, Chile.

2007b Circulación de bienes como indicador de interacción entre las poblaciones de la pampa occidental y sus vecinos. Arqueología en las Pampas (ed. por C. Bayón, A. Pupio, M.I. González, N. Flegenheimer y M. Frére), pp. 345-364. Sociedad Argentina de Antropología, Buenos Aires.

2013 La arqueología del sector occidental de la región pampeana. Trayectoria y reposicionamiento respecto a la arqueología nacional. Revista del Museo de La Plata 13 (87): 7-29.

Berón, M. A., L.H. Luna y R. Barberena

2009 Isotopic Archaeology in the Western Pampas (Argentina): Preliminary Results and Perspectives. International Journal of Osteoarchaeology 19: 250-265.

Bettinger, R.L.

1991 Hunter-gatherers: archaeological and evolutionary theory. Plenum, New York.

Betts, M.W. y T.M. Friesen

2004 Quantifying hunter-gatherer intensification: a zooarchaeological case study from Arctic Canada. Journal of Anthropological Archaeology 23: 357-384.

Binford, L.

1981 Bones: Ancient Men and Modern Myths. Academic Press, New York.

2001 Constructing Frames of Reference: An Analytical Method for Archaeological Theory Building Using Hunter-Gatherer and Environmental Data Sets. University of California Press, London.

Borrero, L.

2002 Arqueología y biogeografía humana en el sur de Mendoza (comentario crítico). Entre Montañas y desiertos: Arqueología del Sur de Mendoza (ed. por A. Gil y G. Neme), pp. 103-113. Sociedad Argentina de Antropología.

Boserup, E.

1965 The Conditions of Agricultural Growth. Aldine, Chicago.

Broughton, J.M.

1994 Late Holocene Resource Intensification in the Sacramento Valley, California: The Vertebrate Evidence. Journal of Archaeological Science 21: 501-514.

1997 Widening diet breadth, declining foraging efficiency, and prehistoric harvest pressure: ichthyofaunal evidence from the Emeryville Shellmound, California. Antiquity 71: 845-862. 
Burger, O., M.J. Hamilton y R. Walker

2005 The prey as patch model: optimal handling of resources with diminishing returns. Journal of Archaeological Science 32: 1147-1158.

Butler, V.L. y S.K. Campbell

2004 Resource Intensification and Resource Depression in the Pacific Northwest of North

America: A Zooarchaeological Review. Journal of World Prehistory 18 (4): 327-405.

Carden, N. y G. Martínez

2014 Diseños fragmentados. Circulación social de imágenes sobre huevos de Rheidae en Pampa y Norpatagonia. Boletín del Museo Chileno de Arte Precolombino 19 (2): 55-75."

David, B. y H. Lourandos

1998 Rock art and socio-demography in northeast Australian prehistory. World Archaeology 30: 193-219.

1999 Landscape as mind: land use, cultural space and change in north Queensland prehistory. Quaternary International 59: 107-123.

Favier Dubois, C.M., F. Borella, L.M. Manzi, M. Cardillo, S. Lanzellotti, F. Scartascini, C. Mariano y E. Borges Vaz

2006 Aproximación regional al registro arqueológico de la costa rionegrina. Arqueología de la costa patagónica. Perspectivas para la conservación (ed. por I. Cruz y M.S. Caracotche), pp. 50-68. Universidad Nacional de la Patagonia Austral, Río Gallegos.

Favier Dubois, C.M., F. Borella y R.H. Tykot

2009 Explorando tendencias en el uso humano del espacio y los recursos en el litoral rionegrino (Argentina) durante el Holoceno medio y tardío. Arqueología de la Patagonia: una mirada desde el último confin (comp. por M. Salemme, F. Santiago, M. Álvarez, E. Piana, M. Vázquez y M.E. Mansur), pp. 985-997. Editorial Utopías, Ushuaia, Tierra del Fuego.

Fisher, J. W.

1995 Bone surface modification in zooarchaeology. Journal of Archaeological Method and Theory 2 (1): 7-68.

Flensborg, G.

2012 Análisis paleopatológico en el curso inferior del río Colorado (Pcia. de Buenos Aires). Exploración y evaluación del estado de salud de sociedades cazadoras-recolectoras en el Holoceno tardío. Tesis Doctoral inédita. Facultad de Ciencias Sociales, UNCPBA, Olavarría.

Gamble, C.S.

1986 The Paleolithic Settlement of Europe. Cambridge University Press. Cambridge.

Gómez Otero, J.

2006 Recursos, dieta y movilidad en la costa centro-septentrional de Patagonia durante el Holoceno medio y tardío. Tesis Doctoral inédita. Facultad de Filosofía y Letras, Universidad de Buenos Aires, Buenos Aires.

González, M.I.

2005 Arqueología de alfareros, cazadores y pescadores pampeanos. Colección de Tesis Doctorales, Sociedad Argentina de Antropología, Buenos Aires. 
González Morales, M.

1991 From Hunter-Gatherers to Food Producers in Northern Spain: Smooth Adaptive Shifts or Revolutionary Change in the Mesolithic. Perspectives on the Past: Theoretical Biases in Mediterranean Hunter-Gatherer Research (ed. por G. Clark), pp. 204-216. University of Pennsylvania Press, Philadelphia.

Goñi, R.A.

2010 Cambio climático y poblamiento humano durante el Holoceno tardío en Patagonia meridional. Una perspectiva arqueológica. Tesis Doctoral inédita. Facultad de Filosofía y Letras, Universidad de Buenos Aires. Buenos Aires.

Gordón, F.

2011 Dinámica poblacional, Conflicto y Violencia en el Norte de Patagonia durante el Holoceno tardío: un Estudio Arqueológico. Tesis Doctoral inédita. Facultad de Ciencias Naturales y Museo, Universidad Nacional de La Plata. La Plata.

Holly, D.H.

2005 The Place of "Others" in Hunter-Gatherer Intensification. American Anthropologist 107 (2): 207-220.

Janetski, J.C.

1997 Fremont Hunting and Resource Intensification in the Eastern Great Basin. Journal of Archaeological Science 24: 1075-1088.

Jones, E.L.

2009 Clime change, patch choice, and intensification at Pont d'Ambon (Dordogne, France) during the Younger Dryas. Quaternary Research 72: 371-376.

Kelly, R.

1995 The Foraging Spectrum: Diversity in Hunter-gatherer Lifeways. Smithsonian Institution Press, Washington.

Leach, H.M.

1999 Intensification in the Pacific. Current Anthropology 40 (3): 311-339.

Loponte, D.

2008 Arqueología del Humedal del Paraná inferior (Bajíos Ribereños Meridionales). Serie Arqueología de la Cuenca del Plata. Instituto de Antropología y Pensamiento Latinoamericano, Secretaría de Cultura de la Nación, Buenos Aires.

Loponte, D. y A. Acosta

2004 Late Holocene hunter-gatherers from the Pampean wetlands, Argentina. Zooarchaeology of South America (ed. por G. Mengoni Goñalons), pp.39-57. BAR, International Series, Oxford.

Loponte, D., A. Acosta y J. Musali

2002 Complexity among Hunter-Gatherers from the Pampean Region, South America. Beyond Affluent Foragers: rethinking hunter-gatherer complexity (ed. por C. Grier, J. Kim y J. Uchiyama), pp. 106-125. Oxbow Books Series, Londres. 
Lourandos, $\mathrm{H}$.

1983 Intensification: a Late Pleistocene-Holocene archaeological sequence from Southwestern Victoria. Archaeology in Oceania 18: 81-97.

1985 Problems with the interpretations of late Holocene changes in Australian prehistory. Archaeology in Oceania 20: 37-39.

1997 Continent of Hunter-Gatherers. New perspectives in Australian prehistory. Cambridge University press, Cambridge.

Lyman, R.L.

1994 Vertebrate Taphonomy. Cambridge Manuals in Archaeology. Cambridge University Press, Cambridge.

2008 Quantitative Paleozoology. Cambridge, Manuals in Archaeology. Cambridge University Press, Cambridge.

Madrid, P. y G. Barrientos

2000 La estructura del registro arqueológico del sitio Laguna Tres Reyes 1 (Provincia de Buenos Aires): Nuevos datos para la interpretación del poblamiento humano en el sudeste de la región pampeana a inicios del Holoceno tardío. Relaciones XXV: 179-206.

Martínez, G.

1999 Tecnología, subsistencia y asentamiento en el curso medio del río Quequén Grande: un enfoque arqueológico. Tesis Doctoral inédita. Universidad de La Plata, La Plata.

2008-2009 Arqueología del curso inferior del río Colorado: estado actual del conocimiento e implicaciones para la dinámica poblacional de cazadores recolectores pampeano-patagónicos. Cazadores-Recolectores del Cono Sur. Revista de Arqueología 3: 71-92.

2010 Hunter-gatherer social interaction Networks in arid landscape (Argentina). Libro de resumenes de la 75th Annual Meeting to the Society for American Archaeology, pp. 163. St. Louis. EE.UU.

Martínez, G. y Q. Mackie

2003-2004 Late Holocene human occupation of the Quequén Grande River valley bottom: settlement systems and an example of a built environment in the Argentine Pampas. Before Farming 1: 178-202.

Martínez, G. y M. Gutiérrez

2004 Tendencias en la explotación humana de la fauna durante el Pleistoceno final y Holoceno en la Región Pampeana (Argentina). Zooarchaeology of South America (ed. por G.L. Mengoni Goñalons), pp. 81-98. BAR Internacional Series 1298. Oxford.

Martínez, G. y G. A. Martínez

2011 Late Holocene environmental dynamics in fluvial and eolian depositional settings: Archaeological record variability at the lower basin of the Colorado river (Argentina). Quaternary International 245 (1): 89-102.

Martínez, G., A. F. Zangrando y L. Prates

2009 Isotopic ecology and human paleodiets in the lower basin of the Colorado river (Buenos Aires province, Argentina). International Journal of Osteoarchaeology: 281-296. 
Martínez, G., G. Armentano, L. Stoessel, G. A. Martínez, A.P. Alcaráz, N. González y F. Santos 2010 Resultados preliminares de la localidad arqueológica San Antonio (curso inferior del río Colorado, pdo. de Villarino, pcia. de Buenos Aires). Mamül Mapu: pasado y presente desde la arqueología pampeana (ed. por M. Berón, L. Luna, M. Bonomo, C. Montalvo, C. Aranda y M. Carrera Aizpitarte), pp. 241-252. Editorial Libros del Espinillo. Ayacucho, Buenos Aires.

Martínez, G., P. Madrid y A. Bonetti

2011 Análisis tecnomorfológico de la alfarería del sitio Loma Ruíz 1 (curso inferior del río Colorado, provincia de Buenos Aires). Libro de resúmenes del VI Congreso de Arqueología de la región Pampeana Argentina, pp. 104. FCNyM-UNLP. La Plata.

Martínez, G., G. Flensborg y P. Bayala

2012 Human corpse manipulation and the body as symbol: a case study from the Eastern Pampa-Patagonia transition (Argentina) during the Final Late Holocene. Journal of Anthropological Archaeology 31: 215-226.

2013 Chronology and human settlement in northeastern Patagonia (Argentina): Patterns of site destruction, intensity of archaeological signal, and population dynamics. Quaternary International: 123-134.

Martínez, G., G.A. Martínez, L. Stoessel, A.P. Alcaráz, F. Santos Valero, G. Flensborg, P. Bayala y J.F. Onorato

2014 Resultados preliminares del sitio Zoko Andi 1. Aportes para la arqueología del curso inferior del río Colorado (Provincia de Buenos Aires). Revista del Museo de Antropología 7 (1): 105-114.

Mazzanti, D.

2006 La constitución de territorios sociales durante el Holoceno tardío. El caso de las sierras de Tandilia. Argentina. Relaciones XXXI: 277-300.

Meltzer, D.J.

1999 Human Responses to Middle Holocene (Altithermal) Climates on the North American Great Plains. Quaternary Research 52: 404-416.

Messineo, $\mathrm{P}$.

2008 Investigaciones arqueológicas en la cuenca superior del arroyo Tapalqué (Partidos de Olavarría y Benito Juárez, Provincia de Buenos Aires). Tesis Doctoral inédita. Facultad de Ciencias Naturales y Museo, Universidad de La Plata, La Plata.

Minnegal, M. y P.D. Dwyer

1998 Intensification and Social Complexity in the Interior Lowlands of Papua New Guinea: A Comparison of Bedamuni and Kubo. Journal of Anthropological Archaeology 17: 375-400.

Miotti, L.

2012 El uso de los recursos faunísticos entre los cazadores-recolectores de Patagonia: tendencias espacio/temporales de las estrategias durante el Holoceno. Archaeofauna 21: 137-160.

Miotti, L. y M. Salemme

1999 Biodiversity, taxonomic richness and specialists-generalists during Late Pleistocene/ Early Holocene times in Pampa and Patagonia (Argentina, Southern South America). Quaternary International 53/54: 53-68. 
Morales, M., R. Barberena, J. Belardi, L. Borrero, V. Cortegoso, V. Durán, A. Gil, R. Goñi, A. Guerci, G. Neme, H. Yacobaccio y M. Zárate

2009 Reviewing human-environment interactions in arid regions of southern South America during the past 3000 years. Palaeogeography, Palaeoclimatology, Palaeoecology 281: 283-295.

Morrison, K.

1994 The intensification of production: archaeological approaches. Journal of Archaeological Method and Theory 1: 111-159.

Nagaoka, L.

2005 Declining foraging efficiency and moa carcass exploitation in southern New Zealand. Journal of Archaeological Science 32: 1328-1338.

Neme, G.

2007 Cazadores-recolectores de altura en los andes meridionales: el alto valle del río Atuel. British Archaeological Reports. International Series.

Neme, G.A. y A.F. Gil

2008 Faunal Exploitation and Agricultural Transitions in the South American Agricultural Limit. International Journal of Osteoarchaeology 18: 293-306.

Otaola, C.

2012 Zooarqueología en la Cordillera del Sur de Mendoza: Un Enfoque Tafonómico. Tesis Doctoral inédita. Universidad de Buenos Aires, Buenos Aires.

2013 ¿Intensificación en la cordillera del sur de Mendoza? Un enfoque tafonómico. Revista Magallania 41 (2): 159-176.

Outram, A.K.

2001 A New Approach to Identifying Bone Marrow and Grease Exploitation: Why the "Indeterminate" Fragments should not be Ignored. Journal of Archaeological Science 28: 401-410.

Politis, G.

2008 The pampas and campos of South America. Handbook of South American Archaeology (ed. por H. Silverman y W. Isbell), pp. 235-260. Springer, New York.

Politis, G., G. Martínez y M. Bonomo

2001 Alfarería Temprana en Sitios de Cazadores-Recolectores de la Región Pampeana (Argentina). Latin American Antiquity 12 (2): 167-181.

Prates, L.

2008 Los indígenas del río Negro. Un enfoque arqueológico. Colección de Tesis Doctorales, Sociedad Argentina de Antropología, Buenos Aires.

Prendergast, M.E., J. Yuan y O. Bar-Yosef

2009 Resource intensification in the Upper Paleolithic: a view from southern China. Journal of Archaeological Science 36: 1027-1037.

Price, T.D. y J.A. Brown

1985 Prehistoric Hunter-Gatherers. The Emergence of Cultural Complexity. Academic Press, New York. 
Quintana, C.A. y D.L. Mazzanti

2001 Selección y aprovechamiento de recursos faunísticos. Cueva Tixi: cazadores y recolectores de las sierras de Tandilia oriental. 1 Geología, paleontología y zooarqueología (ed. por D.L. Mazzanti y C.A. Quintana), pp. 181-209. Laboratorio de arqueología, Universidad Nacional de Mar del Plata. Mar del Plata.

Rivero, D., S. Pastor y M. Medina

2010 Intensificación en las Sierras de Córdoba. El Abrigo Rocoso Quebrada del Real 1 (ca. 6000-500 AP, Córdoba, Argentina). Anales de Arqueología y Etnología de la Universidad Nacional de Cuyo 63-64: 227-246.

Scartascini, F., M. Charo y A. Volpedo

2009 Caracterización de las estrategias de obtención de recursos ícticos a partir del análisis de otolitos. El caso de la costa norte del golfo San Matías (Río Negro). Arqueología de la Patagonia: una mirada desde el último confín (comp. por M. Salemme, F. Santiago, M. Álvarez, E. Piana, M. Vázquez y M.E. Mansur), pp. 845-852. Editorial Utopías, Ushuaia, Tierra del Fuego.

Schäbitz, F.

1994 Holocene climatic variations in northern Patagonia, Argentina. Palaeogeography, paleoclimatology, palaeoecology 109: 287-294.

2003 Estudios polínicos del Cuaternario en las regiones áridas del sur de Argentina. Revista del Museo Argentino de Ciencias Naturales 5 (2): 291-299.

Stoessel, L.

2007 Análisis arqueofaunísticos de los sitios Loma Ruíz 1 y El Tigre (partidos de Villarino y Patagones, provincia de Buenos Aires). Aportes para el conocimiento de la subsistencia en el valle inferior del río Colorado durante el Holoceno tardío. Intersecciones en Antropología 8: 235-251.

2010 Distribución y consumo diferencial de peces en el valle inferior del río Colorado durante el Holoceno tardío. Zooarqueología a principios del siglo XXI: aportes teóricos, metodológicos y casos de estudio (ed. por M.A. Gutiérrez, M. De Nigris, P.M. Fernández, M. Giardina, A.F. Gil, A. Izeta, G. Neme y H.D. Yacobaccio), pp. 333-342. Editorial Libros del Espinillo. Ayacucho, Buenos Aires.

2012a Análisis zooarqueológicos en el curso inferior del río Colorado (provincia de Buenos Aires). A portes para el conocimiento de la subsistencia de cazadores-recolectores en el Holoceno tardío. Tesis Doctoral inédita. Universidad Nacional del Centro, Olavarría.

2012b Consumo de peces en el área ecotonal árida-semiárida del curso inferior del río Colorado (Provincia de Buenos Aires) durante el Holoceno tardío. Relaciones XXXVII: 159-182. 2014a Evaluating Intensity in the Processing of Guanaco (Lama guanicoe) at the Lower Basin of the Colorado River (Argentina): Fragmentation Levels and Fracture Patterns Analysis. International Journal of Osteoarchaeology 24: 51-67.

2014b Tendencias preliminares sobre el consumo de peces durante el Holoceno medio en el área de transición pampeano-patagónica oriental (pcia. de Buenos Aires). Archaeofauna. International Journal of Archaeozoology 24. En prensa.

Stoessel, L., S. Bogan, G. Martínez y F.L. Agnolin

2008 Implicaciones paleoambientales de la presencia del género Ceratophrys (Anura, Ceratophrynae) en contextos arqueológicos de la transición Pampeano-Patagónica en el Holoceno tardío (curso inferior del río Colorado, Argentina). Magallania 36 (2): 217-226 
Williams, E.

1987 Complex hunter-gatherers: a view from Australia. Antiquity 61: 310-321.

Wolverton, $\mathrm{S}$.

2005 The effects the Hypsithermal on prehistoric foraging efficiency in Missouri. American Antiquity 70 (1): 91-106.

Yacobaccio, $\mathrm{H}$.

2006 Intensificación económica y complejidad social en cazadores-recolectores surandinos. Boletín de Arqueología PUCP 10: 305-320.

Zangrando, A.F.

2009 Is fishing intensification a direct route to hunter-gatherer complexity? A case study from the Beagle Channel region (Tierra del Fuego, southern South America). World Archaeology 41 (4): 589-608. 